\title{
Decision on risk-averse dual-channel supply chain under demand disruption
}

DOI:

10.1016/j.cnsns.2017.07.003

\section{Document Version}

Accepted author manuscript

Link to publication record in Manchester Research Explorer

\section{Citation for published version (APA):}

Yan, B., Jin, Z. J., Liu, Y. P., \& Yang, J-B. (2018). Decision on risk-averse dual-channel supply chain under demand disruption. Communications in Nonlinear Science and Numerical Simulation, 55, 206-224.

https://doi.org/10.1016/j.cnsns.2017.07.003

\section{Published in:}

Communications in Nonlinear Science and Numerical Simulation

\section{Citing this paper}

Please note that where the full-text provided on Manchester Research Explorer is the Author Accepted Manuscript or Proof version this may differ from the final Published version. If citing, it is advised that you check and use the publisher's definitive version.

\section{General rights}

Copyright and moral rights for the publications made accessible in the Research Explorer are retained by the authors and/or other copyright owners and it is a condition of accessing publications that users recognise and abide by the legal requirements associated with these rights.

\section{Takedown policy}

If you believe that this document breaches copyright please refer to the University of Manchester's Takedown Procedures [http://man.ac.uk/04Y6Bo] or contact uml.scholarlycommunications@manchester.ac.uk providing relevant details, so we can investigate your claim.

\section{OPEN ACCESS}




\title{
Decision on Risk-averse Dual-channel Supply Chain under Demand
}

\section{Disruption}

\author{
Bo Yan ${ }^{\mathrm{a}, *}$, Zijie Jin ${ }^{\mathrm{a}}$, Yanping Liu ${ }^{\mathrm{a}}$, Jianbo Yang ${ }^{\mathrm{b}}$ \\ ${ }^{a}$ School of Economics and Commerce, South China University of Technology, Guangzhou 510006, China \\ ${ }^{\mathrm{b}}$ Alliance Manchester Business School, The University of Manchester, Manchester M15 6PB, UK
}

\begin{abstract}
We studied dual-channel supply chains using centralized and decentralized decision-making models. We also conducted a comparative analysis of the decisions before and after demand disruption. The study shows that the amount of change in decision-making is a linear function of the amount of demand disruption, and it is independent of the risk-averse coefficient. The optimal sales volume decision of the disturbing supply chain is related to market share and demand disruption in the decentralized decision-making model. The optimal decision is only influenced by demand disruption in the centralized decision-making model. The stability of the sales volume of the two models is related to market share and demand disruption. The optimal system production of the two models shows robustness, but their stable internals are different.
\end{abstract}

Keywords: Demand disruption; Risk-averse; Dual-channel; Stackelberg Game.

\section{Introduction}

More vendors, such as IBM and NIKE, were began to open direct selling channels beyond the traditional sales channels. They combined online and offline channels to expand their sales market penetration. Dual-channel supply chain has become a major type of supply chain. This model has certain advantages, but many challenges also exist. The supply-demand relationship and competition relationship will coexist between the supplier and retailer after an online direct marketing channel opens. Competition may also lead to conflicts between the two channels in terms of cross-channel price and operation. Supply chain decision-makers face certain risks in actual operation, specifically when the external environment of the

\footnotetext{
* Corresponding author: Bo Yan Email addresses: yanbo@scut.edu.cn
} 
supply chain is unstable.

Demand disruptions, which may be caused by many factors, such as disasters, quality issues, and unexpected events, could significantly influence the decision and coordination of supply chains. The retailers and manufacturers in the supply chain will be severely affected by these demand disruptions, which could invalidate original decisions with no demand disruptions [1]. Recent examples of the sudden outbreak of bird flu (H7N9) in China have proven the need to reconstruct the poultry meat supply chain given the declining demand for poultry meat [2]. The major risks caused by demand disruptions include loss of efficiency, competitive disadvantage, and loss of revenue [3]. Most managers choose to avoid risks and consider risk factors in their decisions when facing risks caused by demand disruption. The leader in a risk-averse-leading supply chain plays a primary role in domination and control. The leader's attitude toward risk will timely and strongly influence followers.

Therefore, to operate a dual-channel supply chain successfully, it is important for enterprises to avoid conflicts between traditional distribution channels and online direct selling channels. Enterprises should also make optimal decisions based on the risk-averse attitude of a decision-maker when the external environment of supply chain is unstable.

This paper is organized as follows. The second part provides the description of relevant literature. The third section describes the main models and discusses symbol descriptions. The fourth and fifth sections will explore optimal pricing. Both sections will respectively explore the sales and production decisions in the two supply chain models based on the mathematical model of a dual-channel supply chain in centralized decision-making risk-averse mode and dual-channel supply chain in risk-averse decentralized decision-making model before and after demand disturbances. The sixth part of the research paper provides the summary.

\section{Related References}

People are no longer overly concerned of whether they should set up a dual-channel problem [4-5], but they are more focused on the operational issues of a dual-channel supply chain. Yan and Ghose [6] developed a Bertrand game model played simultaneously to examine the value of forecast information on the willingness of consumers to pay in a 
dual-channel competitive market. Tsay and Agrawal [7] found a reasonable pricing strategy that introduced the online direct selling channel by comparing three models, namely, traditional distribution channel, direct online channel, and a third channel that combines traditional distribution and direct selling; this strategy does not have a negative effect on the supplier's benefits in the traditional distribution channels. By analyzing and comparing dual-channel supply chain pricing under different power structures, Zhang et al. [8] proved the existence of different pricing on the supply chain as a result of different power structures. Several scholars combined the factors of a dual-channel supply chain, such as market demand, price, service, advertising, lead time, and fairness concerns, to study its pricing strategy [9-12]. Some scholars studied a combination of multiple factors. Yao and Liu [13] estimated two models in a dual-channel supply chain; one model for Bertrand competition between suppliers and retailers, and the other model for Stackelberg competition, which is dominated by suppliers. They discussed the same product in different channels of equilibrium pricing strategy when price and service simultaneously influenced the demand.

Demand disruption will have a serious influence on the supply chain ([14-15]). The collaboration between the two channels will become a necessary condition for the dual-channel supply chain to maintain stable operation. By considering the supply chain of one supplier and two competing retailers, Zhang et al. [16] considered using a revenue-sharing contract when demand disturbances occur. Xiao et al. [17] analyzed the coordination of multiple retailers competing in the supply chain during demand disturbance. Zhang et al. [8] discussed the unexpected events in a competing supply chain of multiple retailers and investigated the establishment of a revenue-sharing contract for coordination according to demand disruption. Cao et al. [18] considered a supply chain composed of one supplier and multiple retailers that use the revenue-sharing contract to coordinate cost and demand. Ma and Xie [19] focused on the dynamic pricing game of the duopoly air conditioner market with disturbance in demand and analyzed the influence of disturbance on the dynamic game system. Chen and Zhuang [20] also discussed the management issues of demand disruption, wherein the supply chain is dominated by retailers. However, the above studies focused on traditional distribution channels. Only few studies have focused on dual-channel supply chain. Only Huang et al. [21] analyzed optimal pricing and production 
decision in demand disruption of a dual-channel supply chain using the centralized decision-making model and the supplier-dominated decentralized decision-making model.

Most studies assume that supply chain participants are risk-neutral, whereas some scholars showed through empirical research that not all decision-makers are risk-neutral [22]. The decision of a risk-adverse manager is different from a risk-neutral manager. Choi et al. [23] and Xiao and Choi [24] used the mean-variance theory to discuss the relationship between the decision-making of a retailer with risk characteristic and the expected profit and variance. $\mathrm{Xu}$ et al. [25] established the mean-variance model for risk-averse dual-channel supply chain and assumed that the pricing of a risk-averse channel is lower than a risk-neutral one. Liu et al. [26] studied the effect of risk aversion on the optimal policies of a dual-channel supply chain under complete and asymmetric information cases. However, these studies did not consider dual-channel supply chain in demand disruption.

By taking a wider perspective of the present research situation, domestic and foreign scholars gave more attention to the unexpected events in the supply chain in the recent years and achieved different results. Few studies have integrated dual-channel supply chain, demand disruption, and risk-averse. Thus, further exploration can be conducted in this field.

\section{Model Descriptions}

This paper considers a dual-channel supply chain involving one supplier and one retailer, which is illustrated in Figure 1. Among the supply chain, the supplier owns two channels, one of which is the traditional distribution channel and the other is the direct one. While, the retailer has only one channel. The potential scale of market demand is $\tilde{a}=a+\varepsilon$, where $\mathcal{E}$ follows $N\left(0, \sigma^{2}\right)$ in which $\sigma$ is a constant. The supplier and retailer in the supply chain work as a unified risk-averse decision-making body in the centralized decision-making model, it's coefficient of risk aversion is $k$. While in the decentralized decision-making model, there exists Stackelberg game between the two decision makers, and the supplier acts as the leader, who is risk-averse with the coefficient of risk aversion $k_{s}$, and retailer acts as the follower, who is risk-neutral. 


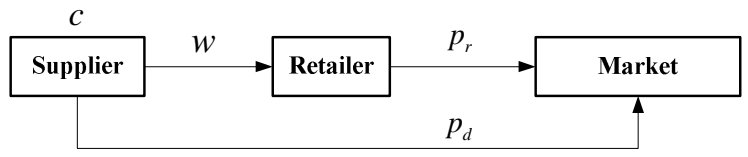

Fig. 1. The structure of the dual-channel supply chain.

The cost of production is $c$, and the product is sold to the retailer at the wholesale price $w$ and directly to the customer at the direct sale price $p_{d}$. The retailer sells commodity to customers at the retail price $p_{r}$. The normal situation is in which the supplier and the retailer formulate production plans according to historical data and market forecasts. The fluctuation of market demand during disasters is discussed, as well as its influences on the decisions of supply chain members.

The model is solved based on the following assumptions:

(1) The productions we considered in the supply chain are single period.

(2) The retailer can only purchase goods from the supplier at the wholesale price.

(3) Information among supply chain members is completely open.

(4) In order to simplify the calculation, and the analysis results will not be effected, we make selling cost, logistics cost, service cost et al. are zero.

(5) The situation of free ride will not be considered.

(6) Supplier undertakes the losses caused by the demand fluctuations of the system.

(7) Decision is effected by market demand more than the risk attitude of the decision-maker.

In the following further discussion, let symbol "* "be the optimal strategy of a supply chain in a centralized decision-making model before the demand disruption while symbol " ", be the one after the demand disruption. Let symbol " $\times$ " be the optimal strategy of a supply chain manager, which is dominated by supplier in a decentralized decision-making model before the demand disruption while symbol " ${ }^{-}$" be the one after the demand disruption.

\section{Dual-channel Supply Chain in the Centralized Decision-making Model}

As supplier and retailer act as a whole in the centralized decision-making model, they make unified planning on the goal of maximizing the system's profit. The situation that a supplier or a retailer makes decision individually doesn't exist. 
Similar to the study of Huang et al. [21], the market demands of both traditional and direct sale channels are assumed to be the linear function of price.

$$
\begin{gathered}
D_{r}=(1-\rho) a-\alpha_{1} p_{r}+\beta p_{d} \\
D_{d}=\rho a-\alpha_{2} p_{d}+\beta p_{r}
\end{gathered}
$$

Subscripts $r$ and $d$ represent the traditional and direct sale channels respectively, $a$ is the potential market demand, $\rho$ is the market share of the direct sale channel, and $\alpha_{1}$ and $\alpha_{2}$ are the individual price effects of the two channels. The supply chain in this study exhibits information symmetry, thus the cross-price effects of the two channels are assumed as $\beta$. As usual, the demand of each channel is more affected by their individual prices than by the cross prices. Therefore, $\alpha_{1}>\beta, \alpha_{2}>\beta$.

The total demand of the two channels is

$$
D=a-\left(\alpha_{1}-\beta\right) p_{r}-\left(\alpha_{2}-\beta\right) p_{d}
$$

\subsection{Centralized Decision without Demand Disruption}

At no demand disruption, the supplier plans based on historical data and market forecasts. The expected profit of the entire supply chain is expressed as

$$
E(\pi)=\left(p_{r}-c\right) D_{r}+\left(p_{d}-c\right) D_{d}
$$

The variance of the expected profit of the entire supply chain is

$$
\operatorname{var}(\pi)=E\left\{[\pi-E(\pi)]^{2}\right\}=\left[\left(p_{d}+(1-\rho) p_{r}-c\right)\right]^{2} \sigma^{2}
$$

Risk-aversive behavior has been widely studied. We adopted the mean-variance model in the present study to measure expected utility by referring to the classical mean-variance criterion introduced by Markowitz [27] and the study conducted by Bannister et al. [28]. The object function is

$$
U(\pi)=E(\pi)-k \sqrt{\operatorname{var}(\pi)} .
$$

By substitution of Equations (1), (2) and (5), it can be easily judged that $U(\pi)$ is a combined concave function with $p_{d}$ and $p_{r}$. The optimal price $p_{d}{ }^{*}$ and $p_{r}{ }^{*}$ of the supply chain system can be obtained through maximizing Equation (6). By substitution of the 
optimal price into Equations (1), (2) and (3), the optimal sales volume of the two channels $D_{d}{ }^{*}, \quad D_{r}^{*}$ and the optimal total production $Q^{*}$ can be obtained.

Theorem 1 Under steady conditions, the optimum pricing, optimum sales volume, and the corresponding optimum output of the supply chain under centralization are

$$
\begin{gathered}
p_{d}{ }^{*}=\frac{\left(\beta+\alpha_{1} \rho-\beta \rho\right)(a-k \sigma)}{2\left(\alpha_{1} \alpha_{2}-\beta^{2}\right)}+\frac{c}{2} \\
p_{r}{ }^{*}=\frac{\left(\alpha_{2}-\alpha_{2} \rho+\beta \rho\right)(a-k \sigma)}{2\left(\alpha_{1} \alpha_{2}-\beta^{2}\right)}+\frac{c}{2} \\
D_{d}^{*}=\frac{\rho(a+k \sigma)-\left(\alpha_{2}-\beta\right) c}{2} \\
D_{r}{ }^{*}=\frac{(1-\rho)(a+k \sigma)-\left(\alpha_{1}-\beta\right) c}{2} \\
Q^{*}=D^{*}=\frac{(a+k \sigma)-\left(\alpha_{1}+\alpha_{2}-2 \beta\right) c}{2}
\end{gathered}
$$

\subsection{Decision with Demand Disruption}

When emergencies occur, market size is disrupted, and its potential demand changes from $a$ to $a+\Delta a, \Delta a$ is the demand disturbance caused by the disaster. Fluctuation in relation to market size is assumed to not eliminate the demand for the product, that is, $a+\Delta a>0$.

When the market is disrupted, the demands of the traditional and direct sale channels are

$$
\begin{gathered}
D_{r}{ }^{\prime}=(1-\rho)(a+\Delta a)-\alpha_{1} p_{r}{ }^{\prime}+\beta p_{d}{ }^{\prime} \\
D_{d}{ }^{\prime}=\rho(a+\Delta a)-\alpha_{2} p_{d}{ }^{\prime}+\beta p_{r}{ }^{\prime}
\end{gathered}
$$

Following the disruption, the total demand is calculated as

$$
D^{\prime}=a+\Delta a-\left(\alpha_{1}-\beta\right) p_{r}{ }^{\prime}-\left(\alpha_{2}-\beta\right) p_{d}{ }^{\prime}
$$

If the actual demand is smaller than the planned output, handling costs would be incurred, whereas if the actual demand is larger, a shortage would be experienced. These assumptions are the same as those of Huang et al. [21]. The handling cost factor is denoted as $u_{1}$, and the shortage cost factor is $u_{2}$. The expected profit of the supply chain under centralization and after the demand disruption is

$$
E\left(\pi^{\prime}\right)=\left(p_{r}{ }^{\prime}-c\right) D_{r}{ }^{\prime}+\left(p_{d}{ }^{\prime}-c\right) D_{d}{ }^{\prime}-u_{1}\left(D^{\prime}-Q^{*}\right)^{+}-u_{2}\left(Q^{*}-D^{\prime}\right)^{+}
$$


In Equation (10), $(x)^{+}=\max \{0, x\}$. The first and second part represents the profit of traditional distribution and direct selling channel after the demand disruption respectively. The third part represents the handling cost when market demand is larger than original planning production after the demand disruption. The fourth part represents the shortage cost when market demand is smaller than original planning production after the demand disruption. As a matter of fact, handling cost and shortage cost don't happen at the same time. It has been proved that when $\Delta a>0, D^{\prime} \geq Q^{*}$ and when $\Delta a<0, D^{\prime} \leq Q^{*}$ in Huang et al. [21], it will not be discussed once more.

Situation 1: When $\Delta a>0$,

$$
E\left(\pi^{\prime}\right)=\left(p_{r}{ }^{\prime}-c\right) D_{r}{ }^{\prime}+\left(p_{d}{ }^{\prime}-c\right) D_{d}{ }^{\prime}-u_{1}\left(D^{\prime}-Q^{*}\right)
$$

In this situation, the variance of the expected profit of the supply chain is

$$
\operatorname{var}\left(\pi^{\prime}\right)=\frac{\left(2 c-2 p_{r}{ }^{\prime}+u_{1}-2 \rho p_{d}{ }^{\prime}+2 \rho p_{r}{ }^{\prime}\right)^{2} \sigma^{2}}{4}
$$

The expected utility function of the supply chain is

$$
\begin{aligned}
& U\left(\pi^{\prime}\right)=E\left(\pi^{\prime}\right)-k \sqrt{\operatorname{var}\left(\pi^{\prime}\right)} \\
& \text { s.t. } \quad D^{\prime} \geq Q^{*}
\end{aligned}
$$

$U\left(\pi^{\prime}\right)$ can easily be proven as the joint concave function of $p_{d}{ }^{\prime}$ and $p_{r}{ }^{\prime}$. In addition, the constraint condition $D^{\prime} \geq Q^{*}$ is linear. Therefore, the expected utility has a unique optimum value. Using Lagrange multiplier $\lambda \geq 0$, the suitable Karush-Kuhn-Tucker (KKT) conditions for Equation (13) are the following:

$$
\left\{\begin{array}{c}
\alpha_{2} p_{d}{ }^{\prime}-\rho(a+\Delta a)-\beta p_{r}{ }^{\prime}+\lambda\left(\alpha_{2}-\beta\right)-\alpha_{2}\left(c-p_{d}{ }^{\prime}\right)+\beta\left(c-p_{r}{ }^{\prime}\right)-u_{1}\left(\alpha_{2}-\beta\right)+\rho k \sigma=0 \\
\alpha_{1} p_{r}{ }^{\prime}-\beta p_{d}{ }^{\prime}+\left(\lambda-u_{1}\right)\left(\alpha_{1}-\beta\right)-\alpha_{1}\left(c-p_{r}{ }^{\prime}\right)+\beta\left(c-p_{d}{ }^{\prime}\right)-(a+\Delta a-k \sigma)(1-\rho)=0 \\
\lambda\left(D^{\prime}-Q^{*}\right)=0 \\
D^{\prime} \geq Q^{*}
\end{array}\right.
$$

Situation 2: When $\Delta a<0$,

$$
E\left(\pi^{\prime}\right)=\left(p_{r}{ }^{\prime}-c\right) D_{r}{ }^{\prime}+\left(p_{d}{ }^{\prime}-c\right) D_{d}{ }^{\prime}-u_{2}\left(Q^{*}-D^{\prime}\right)
$$

In this situation, the variance of the expected profit of the supply chain is 


$$
\operatorname{var}\left(\pi^{\prime}\right)=\frac{\left(-2 c+2 p_{r}{ }^{\prime}-u_{2}+2 \rho p_{d}{ }^{\prime}-2 \rho p_{r}{ }^{\prime}\right) \sigma^{2}}{4}
$$

The expected utility of the supply chain is

$$
\begin{aligned}
& U\left(\pi^{\prime}\right)=E\left(\pi^{\prime}\right)-k \sqrt{\operatorname{var}\left(\pi^{\prime}\right)} \\
& \text { s.t. } \quad D^{\prime} \leq Q^{*}
\end{aligned}
$$

Similar to Situation 1, identifying the following suitable KKT conditions for Equation (17):

$$
\left\{\begin{array}{c}
\alpha_{2} p_{d}{ }^{\prime}-\rho(a+\Delta a)-\beta p_{r}{ }^{\prime}-\lambda\left(\alpha_{2}-\beta\right)-\alpha_{2}\left(c-p_{d}{ }^{\prime}\right)+\beta\left(c-p_{r}{ }^{\prime}\right)+u_{2}\left(\alpha_{2}-\beta\right)+\rho k \sigma=0 \\
\alpha_{1} p_{r}{ }^{\prime}-\beta p_{d}{ }^{\prime}+\left(u_{2}-\lambda\right)\left(\alpha_{1}-\beta\right)-\alpha_{1}\left(c-p_{r}{ }^{\prime}\right)+\beta\left(c-p_{d}{ }^{\prime}\right)-(a+\Delta a-k \sigma)(1-\rho)=0 \\
\lambda\left(Q^{*}-D^{\prime}\right)=0 \\
D^{\prime} \leq Q^{*}
\end{array}\right.
$$

The influence of the market size on decisions is also hypothesized to be more than that of risk attitude. Therefore, $a+\Delta a-k \sigma>0$.

By solving Equations (14) and (18) and combined with Equations (7), (8) and (9), Theorem 2 will be achieved.

Theorem 2 When demand is disrupted, the optimum pricing, the optimum sales volume, and the corresponding optimum output of the supply chain under centralization are:

$$
\begin{aligned}
& p_{d}{ }^{\prime}=\left\{\begin{array}{lr}
\frac{\left(\beta+\alpha_{1} \rho-\beta \rho\right)(a+\Delta a-k \sigma)}{2\left(\alpha_{1} \alpha_{2}-\beta^{2}\right)}+\frac{c+u_{1}}{2}, & \text { if } \Delta a \geq\left(\alpha_{1}+\alpha_{2}-2 \beta\right) u_{1} \\
\frac{\left(\beta+\alpha_{1} \rho-\beta \rho\right)(a+\Delta a-k \sigma)}{2\left(\alpha_{1} \alpha_{2}-\beta^{2}\right)}+\frac{\Delta a}{2\left(\alpha_{1}+\alpha_{2}-2 \beta\right)}+\frac{c}{2}, & \text { if }-\left(\alpha_{1}+\alpha_{2}-2 \beta\right) u_{2}<\Delta a<\left(\alpha_{1}+\alpha_{2}-2 \beta\right) u_{1} \\
\frac{\left(\beta+\alpha_{1} \rho-\beta \rho\right)(a+\Delta a-k \sigma)}{2\left(\alpha_{1} \alpha_{2}-\beta^{2}\right)}+\frac{c-u_{2}}{2}, & \text { if } \Delta a \leq-\left(\alpha_{1}+\alpha_{2}-2 \beta\right) u_{2}
\end{array}\right. \\
& p_{r}{ }^{\prime}=\left\{\begin{array}{lr}
\frac{\left(\alpha_{2}-\alpha_{2} \rho+\beta \rho\right)(a+\Delta a-k \sigma)}{2\left(\alpha_{1} \alpha_{2}-\beta^{2}\right)}+\frac{c+u_{1}}{2}, & \text { if } \Delta a \geq\left(\alpha_{1}+\alpha_{2}-2 \beta\right) u_{1} \\
\frac{\left(\alpha_{2}-\alpha_{2} \rho+\beta \rho\right)(a+\Delta a-k \sigma)}{2\left(\alpha_{1} \alpha_{2}-\beta^{2}\right)}+\frac{\Delta a}{2\left(\alpha_{1}+\alpha_{2}-2 \beta\right)}+\frac{c}{2}, & \text { if }-\left(\alpha_{1}+\alpha_{2}-2 \beta\right) u_{2}<\Delta a<\left(\alpha_{1}+\alpha_{2}-2 \beta\right) u_{1} \\
\frac{\left(\alpha_{2}-\alpha_{2} \rho+\beta \rho\right)(a+\Delta a-k \sigma)}{2\left(\alpha_{1} \alpha_{2}-\beta^{2}\right)}+\frac{c-u_{2}}{2}, & \text { if } \Delta a \leq-\left(\alpha_{1}+\alpha_{2}-2 \beta\right) u_{2}
\end{array}\right. \\
& D_{d}^{\prime}=\left\{\begin{array}{lr}
\frac{\rho(a+\Delta a+k \sigma)-\left(\alpha_{2}-\beta\right)\left(c+u_{1}\right)}{2}, & \text { if } \Delta a \geq\left(\alpha_{1}+\alpha_{2}-2 \beta\right) u_{1} \\
\frac{\rho(a+\Delta a+k \sigma)}{2}-\frac{\left(\alpha_{2}-\beta\right) \Delta a}{2\left(\alpha_{1}+\alpha_{2}-2 \beta\right)}-\frac{\left(\alpha_{2}-\beta\right) c}{2}, & \text { if }-\left(\alpha_{1}+\alpha_{2}-2 \beta\right) u_{2}<\Delta a<\left(\alpha_{1}+\alpha_{2}-2 \beta\right) u_{1} \\
\frac{\rho(a+\Delta a+k \sigma)-\left(\alpha_{2}-\beta\right)\left(c-u_{2}\right)}{2}, & \text { if } \Delta a \leq-\left(\alpha_{1}+\alpha_{2}-2 \beta\right) u_{2}
\end{array}\right.
\end{aligned}
$$




$$
\begin{gathered}
D_{r}{ }^{\prime}=\left\{\begin{array}{lr}
\frac{(1-\rho)(a+\Delta a+k \sigma)-\left(\alpha_{1}-\beta\right)\left(c+u_{1}\right)}{2}, & \text { if } \Delta a \geq\left(\alpha_{1}+\alpha_{2}-2 \beta\right) u_{1} \\
\frac{\left(\alpha_{1}-\beta\right) a-\gamma_{1}(a+\Delta a)}{2\left(\alpha_{1}+\alpha_{2}-2 \beta\right)}-\frac{\left(\alpha_{1}-\beta\right) c}{2}+\frac{(1-\rho) k \sigma}{2}, & \text { if }-\left(\alpha_{1}+\alpha_{2}-2 \beta\right) u_{2}<\Delta a<\left(\alpha_{1}+\alpha_{2}-2 \beta\right) u_{1} \\
\frac{(1-\rho)(a+\Delta a+k \sigma)-\left(\alpha_{1}-\beta\right)\left(c-u_{2}\right)}{2}, & \text { if } \Delta a \leq-\left(\alpha_{1}+\alpha_{2}-2 \beta\right) u_{2}
\end{array}\right. \\
Q^{\prime}=\left\{\begin{array}{lr}
\frac{(a+\Delta a+k \sigma)-\left(\alpha_{1}+\alpha_{2}-2 \beta\right)\left(c+u_{1}\right)}{2}, & \text { if } \Delta a \geq\left(\alpha_{1}+\alpha_{2}-2 \beta\right) u_{1} \\
\frac{a+k \sigma-\left(\alpha_{1}+\alpha_{2}-2 \beta\right) c}{2}, & \text { if }-\left(\alpha_{1}+\alpha_{2}-2 \beta\right) u_{2}<\Delta a<\left(\alpha_{1}+\alpha_{2}-2 \beta\right) u_{1} \\
\frac{(a+\Delta a+k \sigma)-\left(\alpha_{1}+\alpha_{2}-2 \beta\right)\left(c-u_{2}\right)}{2}, & \text { if } \Delta a \leq-\left(\alpha_{1}+\alpha_{2}-2 \beta\right) u_{2}
\end{array}\right.
\end{gathered}
$$

Among them, $\gamma_{1}=\beta-\alpha_{2}+\alpha_{1} \rho+\alpha_{2} \rho-2 \beta \rho$.

Theorem 2 shows that demand disturbance will change the optimal pricing, optimal sales, and corresponding optimum output in the supply chain. After obtaining the derivation calculus to risk adverse coefficient $k$, the relationship between the first derivative and 0 can be easily judged. Conclusion 1 can be easily obtained by combining the relationship between the correlated variables and $k$ with Theorem 1 .

$$
\begin{gathered}
\frac{\partial p_{d}{ }^{*}}{\partial k}=\frac{\partial p_{d}{ }^{\prime}}{\partial k}=\frac{-\left(\beta+\alpha_{1} \rho-\beta \rho\right) \sigma}{2\left(\alpha_{1} \alpha_{2}-\beta^{2}\right)}<0 \quad ; \quad \frac{\partial p_{r}{ }^{*}}{\partial k}=\frac{\partial p_{r}{ }^{\prime}}{\partial k}=\frac{-\left(\alpha_{2}-\alpha_{2} \rho+\beta \rho\right) \sigma}{2\left(\alpha_{1} \alpha_{2}-\beta^{2}\right)}<0 ; \\
\frac{\partial D_{d}{ }^{*}}{\partial k}=\frac{\partial D_{d}{ }^{\prime}}{\partial k}=\frac{\rho \sigma}{2}>0 ; \frac{\partial D_{r}{ }^{*}}{\partial k}=\frac{\partial D_{r}{ }^{\prime}}{\partial k}=\frac{(1-\rho) \sigma}{2}>0 ; \quad \frac{\partial Q^{*}}{\partial k}=\frac{\partial Q^{\prime}}{\partial k}=\frac{\sigma}{2}>0 .
\end{gathered}
$$

Conclusion 1 The pricing strategy and coefficient of risk aversion are inversely proportional before and after demand disruption. The optimum sales volume and optimum total production are proportional to the risk adverse coefficient. The risk aversion attitude toward the supply chain affects the system's optimum strategy in the same manner before and after demand disruption.

Conclusion 1 indicates that regardless of the presence or absence of demand disruption, the price decision of the supply chain decreases with increased coefficient of risk aversion of the supply chain, that is, the more the supply chain avoids risk, the lower the channel price will be. Optimum output increases with the increase in the coefficient of risk aversion. The more the supply chain is afraid of risk, the larger the optimum output will be. The same principle applies to the situation without demand disruption. Conclusion 1 can correct the decision to provide theoretical guidance for the optimum price and optimum output based on 
the risk aversion of the supply chain under any circumstance.

\subsection{Strategy comparison before and after demand disruption}

Theorem 3 can be obtained based on the optimum price before and after demand disruption, which was obtained from Theorems 1 and 2.

Theorem 3 The variation relationship between the optimum direct selling price and optimum retail price of the dual-channel supply chain under centralization before and after the demand disruption is

$$
\begin{aligned}
& p_{d}{ }^{\prime}=\left\{\begin{array}{lr}
p_{d}{ }^{*}+\frac{\left(\beta+\alpha_{1} \rho-\beta \rho\right) \Delta a}{2\left(\alpha_{1} \alpha_{2}-\beta^{2}\right)}+\frac{u_{1}}{2}, & \text { if } \Delta a \geq\left(\alpha_{1}+\alpha_{2}-2 \beta\right) u_{1} \\
p_{d}{ }^{*}+\left[\frac{\beta+\alpha_{1} \rho-\beta \rho}{2\left(\alpha_{1} \alpha_{2}-\beta^{2}\right)}+\frac{1}{2\left(\alpha_{1}+\alpha_{2}-2 \beta\right)}\right] \Delta a, & \text { if }-\left(\alpha_{1}+\alpha_{2}-2 \beta\right) u_{2}<\Delta a<\left(\alpha_{1}+\alpha_{2}-2 \beta\right) u_{1} \\
p_{d}{ }^{*}+\frac{\left(\beta+\alpha_{1} \rho-\beta \rho\right) \Delta a}{2\left(\alpha_{1} \alpha_{2}-\beta^{2}\right)}-\frac{u_{2}}{2}, & \text { if } \Delta a \leq-\left(\alpha_{1}+\alpha_{2}-2 \beta\right) u_{2}
\end{array}\right. \\
& p_{r}{ }^{\prime}=\left\{\begin{array}{lr}
p_{r}{ }^{*}+\frac{\left(\alpha_{2}-\alpha_{2} \rho+\beta \rho\right) \Delta a}{2\left(\alpha_{1} \alpha_{2}-\beta^{2}\right)}+\frac{u_{1}}{2}, & \text { if } \Delta a \geq\left(\alpha_{1}+\alpha_{2}-2 \beta\right) u_{1} \\
p_{r}{ }^{*}+\left[\frac{\alpha_{2}-\alpha_{2} \rho+\beta \rho}{2\left(\alpha_{1} \alpha_{2}-\beta^{2}\right)}+\frac{1}{2\left(\alpha_{1}+\alpha_{2}-2 \beta\right)}\right] \Delta a, & \text { if }-\left(\alpha_{1}+\alpha_{2}-2 \beta\right) u_{2}<\Delta a<\left(\alpha_{1}+\alpha_{2}-2 \beta\right) u_{1} \\
p_{r}{ }^{*}+\frac{\left(\alpha_{2}-\alpha_{2} \rho+\beta \rho\right) \Delta a}{2\left(\alpha_{1} \alpha_{2}-\beta^{2}\right)}-\frac{u_{2}}{2}, & \text { if } \Delta a \leq-\left(\alpha_{1}+\alpha_{2}-2 \beta\right) u_{2}
\end{array}\right.
\end{aligned}
$$

Theorem 3 suggests that the demand disruption under centralization changes the optimum price strategy, both of which could be calculated by adding the linear function of $\Delta a$ based on the original price in stable condition. When the demand fluctuation is within the range of $\left(-\left(\alpha_{1}+\alpha_{2}-2 \beta\right) u_{2},\left(\alpha_{1}+\alpha_{2}-2 \beta\right) u_{1}\right)$, the price that will be adjusted can be regarded as a new market, wherein market size is $\Delta a$ and the marginal cost of production is 0 . When $\Delta a \geq\left(\alpha_{1}+\alpha_{2}-2 \beta\right) u_{1}$ or $\Delta a \leq-\left(\alpha_{1}+\alpha_{2}-2 \beta\right) u_{2}$, the price that will be adjusted can be regarded as a new market, wherein market size is $\Delta a$ and the marginal cost of production is $-u_{1}$ or $u_{2}$.

Theorem 4 can be obtained based on the optimum selling volume of the two channels under centralization before and after the demand disruption obtained from Theorems 1 and 2 .

Theorem 4 The variation relationship of the optimum sales volume of the dual-channel supply chain under centralization before and after the demand disruption is 


$$
\begin{aligned}
& D_{r}{ }^{\prime}=\left\{\begin{array}{lr}
D_{r}^{*}+\frac{(1-\rho) \Delta a-\left(\alpha_{1}-\beta\right) u_{1}}{2}, & \text { if } \Delta a \geq\left(\alpha_{1}+\alpha_{2}-2 \beta\right) u_{1} \\
D_{r}^{*}-\frac{\gamma_{1} \Delta a}{2\left(\alpha_{1}+\alpha_{2}-2 \beta\right)}, & \text { if }-\left(\alpha_{1}+\alpha_{2}-2 \beta\right) u_{2}<\Delta a<\left(\alpha_{1}+\alpha_{2}-2 \beta\right) u_{1} \\
D_{r}^{*}+\frac{(1-\rho) \Delta a+\left(\alpha_{1}-\beta\right) u_{2}}{2}, & \text { if } \Delta a \leq-\left(\alpha_{1}+\alpha_{2}-2 \beta\right) u_{2}
\end{array}\right. \\
& D_{d}{ }^{\prime}=\left\{\begin{array}{lr}
D_{d}{ }^{*}+\frac{\rho \Delta a-\left(\alpha_{2}-\beta\right) u_{1}}{2}, & \text { if } \Delta a \geq\left(\alpha_{1}+\alpha_{2}-2 \beta\right) u_{1} \\
D_{d}{ }^{*}+\frac{\gamma_{1} \Delta a}{2\left(\alpha_{1}+\alpha_{2}-2 \beta\right)}, & \text { if }-\left(\alpha_{1}+\alpha_{2}-2 \beta\right) u_{2}<\Delta a<\left(\alpha_{1}+\alpha_{2}-2 \beta\right) u_{1} \\
D_{d}{ }^{*}+\frac{\rho \Delta a+\left(\alpha_{2}-\beta\right) u_{2}}{2}, & \text { if } \Delta a \leq-\left(\alpha_{1}+\alpha_{2}-2 \beta\right) u_{2}
\end{array}\right.
\end{aligned}
$$

Theorem 4 suggests that the demand disruption under centralization changes the sales volume in two channels, both of which could be calculated by adding the linear function of $\Delta a$. When the demand fluctuation is within the range of $\left(-\left(\alpha_{1}+\alpha_{2}-2 \beta\right) u_{2},\left(\alpha_{1}+\alpha_{2}-2 \beta\right) u_{1}\right)$, the sales volume that will be adjusted can be regarded as a new market, wherein the market size is $\Delta a$ and the marginal cost of production is 0 . When $\Delta a \geq\left(\alpha_{1}+\alpha_{2}-2 \beta\right) u_{1}$ or $\Delta a \leq-\left(\alpha_{1}+\alpha_{2}-2 \beta\right) u_{2}$, the sales volume that will be adjusted can be regarded as a new market, wherein the market size is $\Delta a$ and the marginal cost of production is $u_{1}$ or $-u_{2}$.

Proposition 1 can be obtained from the different conditions of sales volume in different channels and scales of disruption in Theorem 4.

Proposition 1 When the demand fluctuation is within the range of $\left(-\left(\alpha_{1}+\alpha_{2}-2 \beta\right) u_{2},\left(\alpha_{1}+\alpha_{2}-2 \beta\right) u_{1}\right)$, the two channels of the supply chain have the same stability of demand. When the demand fluctuation is beyond the range, the stability of demand is relevant to the demand disruption volume $\Delta a$ and market share $\rho$.

This observation is proven in Appendix 1.

Proposition 1 shows that when the demand disruption is beyond the robust interval, the larger the market share of the channel is, the less stable and the more likely that it will be affected by the environment. The two channels have the same stability when demand disruption is within the robust interval. Stability is relevant to the market share of every distribution selling channel.

The variation relationship of the optimum output of the whole supply chain under 
centralization before and after the demand disruption can be obtained as Theorem 5 combined with Theorems 1 and 2.

Theorem 5 The variation relationship of the optimum output under centralization before and after the demand disruption is

$$
Q^{\prime}=\left\{\begin{array}{lr}
Q^{*}+\frac{\Delta a-\left(\alpha_{1}+\alpha_{2}-2 \beta\right) u_{1}}{2}, & \text { if } \Delta a \geq\left(\alpha_{1}+\alpha_{2}-2 \beta\right) u_{1} \\
Q^{*}, & \text { if }-\left(\alpha_{1}+\alpha_{2}-2 \beta\right) u_{2}<\Delta a<\left(\alpha_{1}+\alpha_{2}-2 \beta\right) u_{1} \\
Q^{*}+\frac{\Delta a+\left(\alpha_{1}+\alpha_{2}-2 \beta\right) u_{2}}{2}, & \text { if } \Delta a \leq-\left(\alpha_{1}+\alpha_{2}-2 \beta\right) u_{2}
\end{array}\right.
$$

Theorem 5 shows that when the demand fluctuation is within the range of $\left(-\left(\alpha_{1}+\alpha_{2}-2 \beta\right) u_{2},\left(\alpha_{1}+\alpha_{2}-2 \beta\right) u_{1}\right)$, the original optimum output shows robustness. This equation also means that the supply chain only need to adjust the price and selling decision of the two channels but not the production quantity under centralization. When the demand fluctuation is beyond the range, the supply chain system needs to adjust production quantity, price and selling strategy at the same time. When $\Delta a \geq\left(\alpha_{1}+\alpha_{2}-2 \beta\right) u_{1}$ or $\Delta a \leq-\left(\alpha_{1}+\alpha_{2}-2 \beta\right) u_{2}$, the sales volume that will be adjusted can be regarded as a new market, wherein the market size is $\Delta a$ and the marginal cost of production is $u_{1}$ or $-u_{2}$.

Conclusion 2 can be obtained from Theorems 3, 4, and 5 .

Conclusion 2 Demand disruption can change the optimum price and optimum sales strategy in two channels. These supply chain strategies need to be adjusted no matter how big the scale of the demand disruption is. However, it can be obtained through a linear function of $\Delta a$ based on the original strategy, which is not relevant to $k$. A robust interval exists within $\left(-\left(\alpha_{1}+\alpha_{2}-2 \beta\right) u_{2},\left(\alpha_{1}+\alpha_{2}-2 \beta\right) u_{1}\right)$, which shows robusticity in the optimum output in the system. When the scale of the demand disruption is beyond the range, the optimum output should be adjusted. However, it is only relevant to disturbance quantity $\Delta a$, and not to risk-averse coefficient $k$.

\section{Dual-channel Supply Chain Decisions in the Decentralized Decision-making Model}

Under decentralization, the supplier, as the Stackelberg leader, initially decides on the optimum direct selling price and the optimum wholesale price, according to his/her 
knowledge about the market and from the retailer, which are based on the principle to maximize profit. The retailer then decides the optimum retail price according to the wholesale price decided by the supplier, which is based also on the principle of profit maximization. The backward induction is conducted in to solve the problem.

\subsection{Decentralized Decision without Demand Disruption}

In the stable market condition, the market demand function of the two channels is as Equations (1) and (2). The optimum output of the supply chain system is as Equation (3).

The expected profits of the supplier and retailer under decentralization are

$$
\begin{gathered}
E\left(\pi_{s}\right)=(w-c) D_{r}+\left(p_{d}-c\right) D_{d} \\
E\left(\pi_{r}\right)=\left(p_{r}-w\right) D_{r}
\end{gathered}
$$

Calculate the decision making of retailer firstly. As the retailer is risk-neutral, the utility function of the retailer is the same as the expected profit function. The reaction function of the optimum retail price could be solved by maximizing Equation (20).

$$
p_{r}=\frac{(1-\rho) a+w \alpha_{1}+\beta p_{d}}{2 \alpha_{1}}
$$

Combine Equations (19) and (20), the variance of the expected profit of the supplier is

$$
\operatorname{var}\left(\pi_{s}\right)=\left[\frac{\gamma_{2} c-\left(\beta+2 \alpha_{1} \rho-\beta \rho\right) p_{d}-(1-\rho) \alpha_{1} w}{2 \alpha_{1}}\right]^{2} \sigma^{2}
$$

Among formula (22), $\gamma_{2}=\alpha_{1}+\beta+\alpha_{1} \rho-\beta \rho$.

As two of the channels in the model are assumed to be profitable, there exists $p_{d} \geq w$.

The utility function of supplier is

$$
\begin{aligned}
& \max U_{s}\left(\pi_{s}\right)=E\left(\pi_{s}\right)-k_{s} \sqrt{\operatorname{var}\left(\pi_{s}\right)} \\
& \text { s.t. } \quad p_{d} \geq w
\end{aligned}
$$

$U_{s}\left(\pi_{s}\right)$ can easily be evaluated as a joint concave function of $p_{d}$ and $w$. In addition, with the constraint condition $p_{d} \geq w$ as linear, $U_{s}\left(\pi_{s}\right)$ has the unique optimum solution. With the Lagrange multiplier $\lambda \geq 0$, the KKT conditions are 


$$
\left\{\begin{array}{c}
\frac{\left(\beta^{2}-2 \alpha_{1} \alpha_{2}+\alpha_{1} \beta\right) c-2\left(\beta^{2}-2 \alpha_{1} \alpha_{2}\right) p_{d}+\left(k_{s} \sigma-a\right)\left(\beta+2 \alpha_{1} \rho-\beta \rho\right)}{2 \alpha_{1}}-(\lambda+\beta w)=0 \\
\frac{2 \lambda+(1-\rho)\left(k_{s} \sigma-a\right)+\left(\beta-\alpha_{1}\right) c-2 \beta p_{d}+2 \alpha_{1} w}{2}=0 \\
\lambda\left(p_{d}-w\right)=0 \\
p_{d} \geq w
\end{array}\right.
$$

Theorem 6 could be obtained by solving Equation (24) and combining Equation (21).

Theorem 6 In a dual-channel supply chain under decentralization without demand disruption, the optimum direct selling price and the optimum wholesale price for the supplier and the optimum retail price for the retailer are defined as follows:

$$
\begin{gathered}
p_{d}^{\times}=\left\{\begin{array}{lr}
\frac{\gamma_{2}\left(a-k_{s} \sigma\right)}{2 \gamma_{3}}+\frac{c}{2}, & \text { if } 0<\rho<\rho^{0} \\
\frac{\left(\beta+\alpha_{1} \rho-\beta \rho\right)\left(a-k_{s} \sigma\right)}{2\left(\alpha_{1} \alpha_{2}-\beta^{2}\right)}+\frac{c}{2}, & \text { if } \rho^{0} \leq \rho<1
\end{array}\right. \\
w^{\times}=\left\{\begin{array}{lr}
\frac{\gamma_{2}\left(a-k_{s} \sigma\right)}{2 \gamma_{3}}+\frac{c}{2}, & \text { if } 0<\rho<\rho^{0} \\
\frac{\left(\alpha_{2}-\alpha_{2} \rho+\beta \rho\right)\left(a-k_{s} \sigma\right)}{2\left(\alpha_{1} \alpha_{2}-\beta^{2}\right)}+\frac{c}{2}, & \text { if } \rho^{0} \leq \rho<1
\end{array}\right. \\
p_{r}^{\times}= \begin{cases}\frac{(1-\rho)\left(4 \alpha_{1} \alpha_{2}-\beta^{2}+\alpha_{1}^{2}\right)+2 \alpha_{1}\left(\alpha_{1}-\beta+2 \beta \rho\right)}{4 \alpha_{1} \gamma_{3}}-\frac{\gamma_{2} k_{s} \sigma}{4 \alpha_{1} \gamma_{3}}+\frac{\alpha_{1}+\beta}{4 \alpha_{1}} c, & \text { if } 0<\rho<\rho^{0} \\
\frac{(1-\rho)\left[\left(3 \alpha_{1} \alpha_{2}-\beta^{2}\right) a-\left(\alpha_{1} \alpha_{2}+\beta^{2}\right) k_{s} \sigma\right]+2 \alpha_{1} \beta \rho\left(a-k_{s} \sigma\right)}{4 \alpha_{1}\left(\alpha_{1} \alpha_{2}-\beta^{2}\right)}+\frac{\alpha_{1}+\beta}{4 \alpha_{1}} c, & \text { if } \rho^{0} \leq \rho<1\end{cases}
\end{gathered}
$$

Among them, $\gamma_{3}=\alpha_{1}^{2}-2 \alpha_{1} \beta+2 \alpha_{1} \alpha_{2}-\beta^{2}$.

Theorem 6 suggests that a critical value $\rho^{0}$ exists in a dual-channel supply chain under decentralization, which contributes to the differences in the decisions of the supplier and retailer. When the market share of the direct sale channel is smaller than $\rho^{0}$, the direct selling price of the supplier is equal to the wholesale price in the distribution channel. When the market share of the direct sale channel is larger than $\rho^{0}$, the direct selling price of the supplier is higher than the wholesale price.

Similar to the actual conditions under decentralization, the price will decrease when the direct sale channel has a relatively small market share, thereby attracting customers. However, the minimum price will not be lower than the distribution price. When the direct sale channel 
has a relatively large market share, the price in the distribution channel will decrease, which will capture the market. Consequently, the direct selling price will be higher than the distribution price.

Theorem 7 can be obtained by combining Theorem 6, Equations (1), (2) and (3).

Theorem 7 The optimum sales volume and optimum output of the two channels under decentralization without demand disruption are

$$
\begin{gathered}
D_{d}^{\times}= \begin{cases}\frac{a\left[2 \alpha_{1}\left(\alpha_{1}^{2}-\alpha_{1} \beta+\gamma_{3}\right)-\left(6 \alpha_{1}^{2} \alpha_{2}-9 \alpha_{1}^{2} \beta+4 \alpha_{1}^{3}+\beta^{3}-2 \alpha_{1} \alpha_{2} \beta\right)(1-\rho)\right]}{4 \alpha_{1}}- \\
\frac{\left(\beta^{2}+\alpha_{1} \beta-2 \alpha_{1} \alpha_{2}\right) k_{s} \sigma}{4 \alpha_{1} \gamma_{3}}+\frac{\left(\beta^{2}+\alpha_{1} \beta-2 \alpha_{1} \alpha_{2}\right) c}{4 \alpha_{1}}, & \text { if } 0<\rho<\rho^{0} \\
\frac{\left(\beta+2 \alpha_{1} \rho-\beta \rho\right)\left(a+k_{s} \sigma\right)+\left(\beta^{2}-2 \alpha_{1} \alpha_{2}+\alpha_{1} \beta\right) c}{4 \alpha_{1}}, & \text { if } \rho^{0} \leq \rho<1\end{cases} \\
D_{r}^{\times}= \begin{cases}\frac{(1-\rho) a}{2}-\frac{\gamma_{2}\left(\alpha_{1}-\beta\right)\left(a-k_{s} \sigma\right)}{4 \gamma_{3}}-\frac{\left(\alpha_{1}-\beta\right) c}{4}, & \text { if } 0<\rho<\rho^{0} \leq \rho<1 \\
\frac{(1-\rho)\left(a+k_{s} \sigma\right)-\left(\alpha_{1}-\beta\right) c}{4}, & \end{cases}
\end{gathered}
$$

The first derivative of risk aversion coefficient $k_{s}$ of the optimum decision in Theorems 6 and 7 is calculated.

Theorems 6 and 7 illustrate that the price decisions and expected profits of members in a dual-channel supply chain under decentralization are related to market share $\rho$. When $\rho$ fluctuates in different intervals, the strategies of the supply chain will also differ. Thus, to make an appropriate decision, a manager should consider the internal and external environment and assess market distribution.

\subsection{Decentralized Decision with Demand Disruption}

With the assumption that under decentralization, the fluctuation of market size is a common knowledge to the supplier and retailer, the market demands for the two channels under demand disruption are

$$
\begin{gathered}
\overline{D_{r}}=(1-\rho)(a+\Delta a)-\alpha_{1} \overline{p_{r}}+\beta \overline{p_{d}} \\
\overline{D_{d}}=\rho(a+\Delta a)-\alpha_{2} \overline{p_{d}}+\beta \overline{p_{r}}
\end{gathered}
$$

The total demand after the disruption is 


$$
\bar{D}=(a+\Delta a)-\left(\alpha_{1}-\beta\right) \overline{p_{r}}-\left(\alpha_{2}-\beta\right) \overline{\beta p_{d}}
$$

The expected profit functions of the retailer after the disruption is

$$
E\left(\overline{\pi_{r}}\right)=\left(\overline{p_{r}}-\bar{w}\right) \overline{D_{r}}
$$

The expected profit functions of the supplier included treatment cost factor $u_{1}$ and stock out cost factor $u_{2}$ after the disruption is

$$
E\left(\overline{\pi_{s}}\right)=(\bar{w}-c) \overline{D_{r}}+\left(\overline{p_{d}}-c\right) \overline{D_{d}}-u_{1}\left(\bar{D}-Q^{\times}\right)^{+}-u_{2}\left(Q^{\times}-\bar{D}\right)^{+}
$$

The first part of Equation (29) represents the profit of supplier in traditional distribution channel. The second part represents the profit of supplier in online direct selling channel. The third part represents the loss of stock out when demand is larger than original production after disruption. The fourth part represents the treatment cost when demand is smaller than original production after disruption.

Backward induction is used to solve the problem. In the second phase of the Stackelberg game, the retailer maximizes Equation (28) to set the optimum retail price. The reaction function of the optimum retail price is

$$
\overline{p_{r}}=\frac{(1-\rho)(a+\Delta a)+\bar{w} \alpha_{1}+\beta \overline{p_{d}}}{2 \alpha_{1}}
$$

In the first phase of the Stackelberg game, the supplier sets the optimum wholesale price and the optimum direct selling price to maximize his/her own profit.

Situation 1: When $\Delta a>0$, that is, the actual demand is more than the planned output, the supplier must pay for the shortage cost. The function of the supplier's expected profit is

$$
E\left(\overline{\pi_{s}}\right)=(\bar{w}-c) \overline{D_{r}}+\left(\overline{p_{d}}-c\right) \overline{D_{d}}-u_{1}\left(\bar{D}-Q^{\times}\right)
$$

Combined with Equation (30), the variance of the supplier's expected profit is

$$
\operatorname{var}\left(\overline{\pi_{s}}\right)=\left\{\frac{\gamma_{2}\left(u_{1}+2 c\right)-2\left(\beta+2 \alpha_{1} \rho-\beta \rho\right) \overline{p_{d}}}{4 \alpha_{1}}-\frac{(1-\rho) \bar{w}}{2}\right\}^{2} \sigma^{2}
$$

The utility function of the supplier is 


$$
\begin{array}{ll}
\max U_{s}\left(\overline{\pi_{s}}\right) & =E\left(\overline{\pi_{s}}\right)-k_{s} \sqrt{\operatorname{var}\left(\overline{\pi_{s}}\right)} \\
\text { s.t. } & \bar{D} \geq Q^{\times} \\
& \overline{p_{d}} \geq \bar{w}
\end{array}
$$

After calculating the Equation (33), the object function $U_{s}\left(\overline{\pi_{s}}\right)$ is easily demonstrated as the joint concave function of $\overline{p_{d}}$ and $\bar{w}$. To solve the previously mentioned optimization problem with constraint, Lagrange multipliers $\lambda_{1} \geq 0, \lambda_{2} \geq 0$ are used. Their KKT conditions are

$$
\left\{\begin{array}{c}
\frac{\left(c+u_{1}-\lambda_{1}\right)\left(\beta^{2}-2 \alpha_{1} \alpha_{2}+\alpha_{1} \beta\right)-\left(\Delta a+a-k_{s} \sigma\right)\left(\beta+2 \alpha_{1} \rho-\beta \rho\right)+2\left(2 \alpha_{1} \alpha_{2}-\beta^{2}\right) \overline{p_{d}}}{2 \alpha_{1}}-\left(\lambda_{2}+\beta \bar{w}\right)=0 \\
\frac{\left(c+u_{1}-\lambda_{1}\right)\left(\beta-\alpha_{1}\right)-(1-\rho)\left(\Delta a+a-k_{s} \sigma\right)}{2}+\left(\alpha_{1} \bar{w}-\beta \overline{p_{d}}+\lambda_{2}\right)=0 \\
\lambda_{1}\left(\bar{D}-Q^{\times}\right)=0 \\
\lambda_{2}\left(\overline{p_{d}}-\bar{w}\right)=0 \\
\bar{D} \geq Q^{\times} \\
\overline{p_{d}} \geq \bar{w}
\end{array}\right.
$$

Situation 2: When $\Delta a<0$, that is, the actual demand is less than the planned output, the supplier must pay for the handling cost. The function and variance of the expected profit of the supplier are

$$
\begin{gathered}
E\left(\overline{\pi_{s}}\right)=(\bar{w}-c) \overline{D_{r}}+\left(\overline{p_{d}}-c\right) \overline{D_{d}}-u_{2}\left(Q^{\times}-\bar{D}\right) \\
\operatorname{var}\left(\overline{\pi_{s}}\right)=\left\{\frac{\gamma_{2}\left(u_{2}-2 c\right)+2\left(\beta+2 \alpha_{1} \rho-\beta \rho\right) \overline{p_{d}}}{4 \alpha_{1}}+\frac{(1-\rho) \bar{w}}{2}\right\}^{2} \sigma^{2}
\end{gathered}
$$

The utility function of the supplier is

$$
\begin{array}{ll}
\max U_{s}\left(\overline{\pi_{s}}\right) & =E\left(\overline{\pi_{s}}\right)-k_{s} \sqrt{\operatorname{var}\left(\overline{\pi_{s}}\right)} \\
\text { s.t. } & \bar{D} \leq Q^{\times} \\
& \overline{p_{d}} \geq \bar{w}
\end{array}
$$

Similar to Equation (34), the KKT conditions are 


$$
\left\{\begin{array}{c}
\frac{\left(c-u_{2}+\lambda_{1}\right)\left(\beta^{2}-2 \alpha_{1} \alpha_{2}+\alpha_{1} \beta\right)-\left(\Delta a+a+k_{s} \sigma\right)\left(\beta+2 \alpha_{1} \rho-\beta \rho\right)+2\left(2 \alpha_{1} \alpha_{2}-\beta^{2}\right) \overline{p_{d}}}{2 \alpha_{1}}-\left(\lambda_{2}+\beta \bar{w}\right)=0 \\
\frac{\left(c-u_{2}+\lambda_{1}\right)\left(\beta-\alpha_{1}\right)-(1-\rho)\left(\Delta a+a+k_{s} \sigma\right)}{2}+\left(\alpha_{1} \bar{w}-\beta \overline{p_{d}}+\lambda_{2}\right)=0 \\
\lambda_{1}\left(\bar{D}-Q^{\times}\right)=0 \\
\lambda_{2}\left(\overline{p_{d}}-\bar{w}\right)=0 \\
\bar{D} \leq Q^{\times} \\
\overline{p_{d}} \geq \bar{w}
\end{array}\right.
$$

Theorem 8 would be drawn by solving Equations (34), (38), and (30).

Theorem 8 When demand disruption occurs, the optimum decisions of the supplier as the leader and the retailer as the follower in a dual-channel supply chain under decentralization are

When $\Delta a \geq \psi u_{1}$ :

$$
\begin{gathered}
\overline{p_{d}}= \begin{cases}\frac{\gamma_{2}\left(a+\Delta a-k_{s} \sigma\right)}{2 \gamma_{3}}+\frac{c+u_{1}}{2}, & \text { if } 0<\rho<\rho^{0} \\
\frac{\left(\beta+\alpha_{1} \rho-\beta \rho\right)\left(a+\Delta a-k_{s} \sigma\right)}{2\left(\alpha_{1} \alpha_{2}-\beta^{2}\right)}+\frac{c+u_{1}}{2}, & \text { if } \rho^{0} \leq \rho<1\end{cases} \\
\bar{w}= \begin{cases}\frac{\gamma_{2}\left(a+\Delta a-k_{s} \sigma\right)}{2 \gamma_{3}}+\frac{c+u_{1}}{2}, & \text { if } 0<\rho<\rho^{0} \\
\frac{\left(\alpha_{2}-\alpha_{2} \rho+\beta \rho\right)\left(a+\Delta a-k_{s} \sigma\right)}{2\left(\alpha_{1} \alpha_{2}-\beta^{2}\right)}+\frac{c+u_{1}}{2}, & \text { if } \rho^{0} \leq \rho<1\end{cases} \\
\overline{p_{r}}= \begin{cases}\frac{\left[(1-\rho)\left(-\gamma_{3}-2 \alpha_{1} \alpha_{2}\right)-2 \alpha_{1}\left(\alpha_{1}+\beta \rho\right)\right](a+\Delta a)}{4 \alpha_{1} \gamma_{3}}-\frac{\left(\alpha_{1}+\beta\right) \gamma_{1} k_{s} \sigma}{4 \alpha_{1} \gamma_{3}}+\frac{\left(\alpha_{1}+\beta\right)\left(c+u_{1}\right)}{4 \alpha_{1}}, \\
\text { if } 0<\rho<\rho^{0} \\
\frac{\left[(1-\rho)\left(3 \alpha_{1} \alpha_{2}-\beta^{2}\right)+2 \alpha_{1} \beta \rho\right](a+\Delta a)}{4 \alpha_{1}\left(\alpha_{1} \alpha_{2}-\beta^{2}\right)}+\frac{\left(\alpha_{1}+\beta\right)\left(c+u_{1}\right)}{4 \alpha_{1}}-\frac{\left[(1-\rho)\left(\alpha_{1} \alpha_{2}+\beta^{2}\right)+2 \alpha_{1} \beta \rho\right] k_{s} \sigma}{4 \alpha_{1}\left(\alpha_{1} \alpha_{2}-\beta^{2}\right)}, \\
\text { if } \rho^{0} \leq \rho<1\end{cases}
\end{gathered}
$$

When $-\psi u_{2}<\Delta a<\psi u_{1}$ :

$$
\overline{p_{d}}= \begin{cases}\frac{\gamma_{2}\left(a+2 \Delta a-k_{s} \sigma\right)}{2 \gamma_{3}}+\frac{c}{2}, & \text { if } 0<\rho<\rho^{0} \\ \frac{\left(\beta+\alpha_{1} \rho-\beta \rho\right)\left(a+\Delta a-k_{s} \sigma\right)}{2\left(\alpha_{1} \alpha_{2}-\beta^{2}\right)}+\frac{\gamma_{2} \Delta a}{2 \gamma_{3}}+\frac{c}{2}, & \text { if } \rho^{0} \leq \rho<1\end{cases}
$$




$$
\begin{gathered}
\bar{w}= \begin{cases}\frac{\gamma_{2}\left(a+2 \Delta a-k_{s} \sigma\right)}{2 \gamma_{3}}+\frac{c}{2}, & \text { if } 0<\rho<\rho^{0} \\
\frac{\left(\alpha_{2}-\alpha_{2} \rho+\beta \rho\right)\left(a+\Delta a-k_{s} \sigma\right)}{2\left(\alpha_{1} \alpha_{2}-\beta^{2}\right)}+\frac{\gamma_{2} \Delta a}{2 \gamma_{3}}+\frac{c}{2}, & \text { if } \rho^{0} \leq \rho<1\end{cases} \\
\overline{p_{r}}= \begin{cases}\frac{\left(\alpha_{1}+\alpha_{2}-\alpha_{2} \rho+\beta \rho\right)(a+\Delta a)}{\gamma_{3}}-\frac{\gamma_{2}\left(\alpha_{1}+\beta\right)\left(k_{s} \sigma+a\right)}{4 \alpha_{1} \gamma_{3}}+\frac{\left(\alpha_{1}+\beta\right) c}{4 \alpha_{1}}, & \text { if } 0<\rho<\rho^{0} \\
\frac{\left[\left(3 \alpha_{1} \alpha_{2}-\beta^{2}\right)(1-\rho)+2 \alpha_{1} \beta \rho\right](a+\Delta a)}{4 \alpha_{1}\left(\alpha_{1} \alpha_{2}-\beta^{2}\right)}+\frac{\gamma_{2}\left(\alpha_{1}+\beta\right) \Delta a}{4 \alpha_{1} \gamma_{3}}-\frac{\left[\left(\alpha_{1} \alpha_{2}+\beta^{2}\right)(1-\rho)+2 \alpha_{1} \beta \rho\right] k_{s} \sigma}{4 \alpha_{1}\left(\alpha_{1} \alpha_{2}-\beta^{2}\right)}+\frac{\left(\alpha_{1}+\beta\right) c}{4 \alpha_{1}} \\
\text { if } \rho^{0} \leq \rho<1\end{cases}
\end{gathered}
$$

When $\Delta a \leq-\psi u_{2}$ :

$$
\begin{aligned}
& \overline{p_{d}}= \begin{cases}\frac{\gamma_{2}\left(a+\Delta a-k_{s} \sigma\right)}{2 \gamma_{3}}+\frac{c-u_{2}}{2}, & \text { if } 0<\rho<\rho^{0} \\
\frac{\left(\beta+\alpha_{1} \rho-\beta \rho\right)\left(a+\Delta a-k_{s} \sigma\right)}{2\left(\alpha_{1} \alpha_{2}-\beta^{2}\right)}+\frac{c-u_{2}}{2}, & \text { if } \rho^{0} \leq \rho<1\end{cases} \\
& \bar{w}= \begin{cases}\frac{\gamma_{2}\left(a+\Delta a-k_{s} \sigma\right)}{2 \gamma_{3}}+\frac{c-u_{2}}{2}, & \text { if } 0<\rho<\rho^{0} \\
\frac{\left(\alpha_{2}-\alpha_{2} \rho+\beta \rho\right)\left(a+\Delta a-k_{s} \sigma\right)}{2\left(\alpha_{1} \alpha_{2}-\beta^{2}\right)}+\frac{c-u_{2}}{2}, & \text { if } \rho^{0} \leq \rho<1\end{cases} \\
& \overline{p_{r}}=\left\{\begin{array}{l}
-\frac{\left[\left(\gamma_{3}+2 \alpha_{1} \alpha_{2}\right)(1-\rho)+2 \alpha_{1}\left(\alpha_{1}+\beta \rho\right)\right](a+\Delta a)}{4 \alpha_{1} \gamma_{3}}-\frac{\left(\alpha_{1}+\beta\right) \gamma_{1} k_{s} \sigma}{4 \alpha_{1} \gamma_{3}}+\frac{\left(\alpha_{1}+\beta\right)\left(c-u_{2}\right)}{4 \alpha_{1}}, \\
\text { if } 0<\rho<\rho^{0} \\
\frac{\left[(1-\rho)\left(3 \alpha_{1} \alpha_{2}-\beta^{2}\right)+2 \alpha_{1} \beta \rho\right](a+\Delta a)}{4 \alpha_{1}\left(\alpha_{1} \alpha_{2}-\beta^{2}\right)}-\frac{\left[(1-\rho)\left(\alpha_{1} \alpha_{2}+\beta^{2}\right)+2 \alpha_{1} \beta \rho\right] k_{s} \sigma}{4 \alpha_{1}\left(\alpha_{1} \alpha_{2}-\beta^{2}\right)}+\frac{\left(\alpha_{1}+\beta\right)\left(c-u_{2}\right)}{4 \alpha_{1}}, \\
\text { if } \rho^{0} \leq \rho<1
\end{array}\right.
\end{aligned}
$$

where $\psi=\frac{\alpha_{1}^{2}+2 \alpha_{1} \alpha_{2}-2 \alpha_{1} \beta-\beta^{2}}{\alpha_{1}+\beta+\alpha_{1} \rho-\beta \rho}, \rho^{0}=\frac{\alpha_{2}-\beta}{\alpha_{1}+\alpha_{2}-2 \beta}$.

Theorem 8 reveals that the price decisions of a dual-channel supply chain under decentralization are related not only to $\Delta a$, but also to $\rho$ when market demand disruption occurs.

When $\Delta a$ fluctuates within the range of $\left(-\psi u_{2}, \psi u_{1}\right)$, the optimum decisions are the same for the dual-channel supply chain, regardless if the changed demand is higher or lesser than the original planned output. The supply chain must perform different measures based on the degree of demand disruption when $\Delta a$ is beyond the specified range. Regardless of the 
fluctuation degree of the market size, price strategy varies from the situation without disruption and the variance always corresponds to the linear function of $\Delta a$.

Theorem 8 also shows that regardless of the degree of demand disruption, the direct selling price is the same as the wholesale price when $0<\rho<\rho^{0}$. When $\rho^{0} \leq \rho<1$, the direct selling price is higher than the wholesale price. This situation is similar to that of a dual-channel supply chain under decentralization without demand disruption.

Theorem 9 When demand disruption occurs, the optimum decisions of the optimal sales volume and production plan are:

When $\Delta a \geq \psi u_{1}$ :

$$
\begin{aligned}
& \overline{D_{r}}= \begin{cases}\frac{\left[\gamma_{4}(1-\rho)-2 \alpha_{1}\left(\alpha_{1}-\beta\right)\right](a+\Delta a)}{4 \gamma_{3}}+\frac{\left(\alpha_{1}-\beta\right) \gamma_{1} k_{s} \sigma}{4 \gamma_{3}}-\frac{\left(\alpha_{1}-\beta\right)\left(c+u_{1}\right)}{4}, & \text { if } 0<\rho<\rho^{0} \\
\frac{(1-\rho)\left(a+\Delta a+k_{s} \sigma\right)-\left(\alpha_{1}-\beta\right)\left(c+u_{1}\right)}{4}, & \text { if } \rho^{0} \leq \rho<1\end{cases} \\
& \overline{D_{d}}= \begin{cases}\frac{\left[2 \alpha_{1}\left(2 \alpha_{1}^{2}-3 \alpha_{1} \beta+2 \alpha_{1} \alpha_{2}-\beta^{2}\right)-\left(6 \alpha_{1}^{2} \alpha_{2}-9 \alpha_{1}^{2} \beta+4 \alpha_{1}^{3}+\beta^{3}-2 \alpha_{1} \alpha_{2} \beta\right)(1-\rho)\right](a+\Delta a)}{4 \alpha_{1} \gamma_{3}}- \\
\frac{\gamma_{2}\left(\beta^{2}+\alpha_{1} \beta-2 \alpha_{1} \alpha_{2}\right) k_{s} \sigma}{4 \alpha_{1} \gamma_{3}}+\frac{\left(\beta^{2}+\alpha_{1} \beta-2 \alpha_{1} \alpha_{2}\right)\left(c+u_{1}\right)}{4 \alpha_{1}}, & \text { if } 0<\rho<\rho^{0} \\
\frac{\left(\beta+2 \alpha_{1} \rho-\beta \rho\right)\left(a+\Delta a+k_{s} \sigma\right)+\left(\beta^{2}+\alpha_{1} \beta-2 \alpha_{1} \alpha_{2}\right)\left(c+u_{1}\right)}{4 \alpha_{1}}, & \text { if } \rho^{0} \leq \rho<1\end{cases}
\end{aligned}
$$

When $-\psi u_{2}<\Delta a<\psi u_{1}$ :

$$
\begin{gathered}
\overline{D_{r}}= \begin{cases}\frac{\gamma_{2}\left(\alpha_{1}-\beta\right)\left(a+k_{s} \sigma\right)}{4 \gamma_{3}}-\frac{\gamma_{1}(a+\Delta a) \alpha_{1}}{\gamma_{3}}-\frac{\left(\alpha_{1}-\beta\right) c}{4}, & \text { if } 0<\rho<\rho^{0} \\
\frac{\left(\alpha_{1}-\beta\right) \gamma_{2} a}{4 \gamma_{3}}-\frac{\alpha_{1} \gamma_{1}(a+\Delta a)}{2 \gamma_{3}}+\frac{(1-\rho) k_{s} \sigma}{4}-\frac{\left(\alpha_{1}-\beta\right) c}{4}, & \text { if } \rho^{0} \leq \rho<1\end{cases} \\
\overline{D_{d}}= \begin{cases}\frac{\gamma_{1}(a+\Delta a) \alpha_{1}}{\gamma_{3}}-\frac{\gamma_{2}\left(\beta^{2}+\alpha_{1} \beta-2 \alpha_{1} \alpha_{2}\right)\left(a+k_{s} \sigma\right)}{4 \alpha_{1} \gamma_{3}}+\frac{\left(\beta^{2}+\alpha_{1} \beta-2 \alpha_{1} \alpha_{2}\right) c}{4 \alpha_{1}}, & \text { if } 0<\rho<\rho^{0} \\
\frac{\gamma_{1}(a+\Delta a) \alpha_{1}}{2 \gamma_{3}}-\frac{a \gamma_{2}\left(\beta^{2}+\alpha_{1} \beta-2 \alpha_{1} \alpha_{2}\right)}{4 \alpha_{1} \gamma_{3}}+\frac{\left(\beta^{2}+\alpha_{1} \beta-2 \alpha_{1} \alpha_{2}\right)\left(c-k_{s} \sigma\right)}{4 \alpha_{1}}, & \text { if } \rho^{0} \leq \rho<1\end{cases}
\end{gathered}
$$

When $\Delta a \leq-\psi u_{2}$ : 


$$
\begin{aligned}
& \overline{D_{r}}= \begin{cases}\frac{\left[\gamma_{4}(1-\rho)-2 \alpha_{1}\left(\alpha_{1}-\beta\right)\right](a+\Delta a)}{4 \gamma_{3}}+\frac{\left(\alpha_{1}-\beta\right) \gamma_{2} k_{s} \sigma}{4 \gamma_{3}}-\frac{\left(\alpha_{1}-\beta\right)\left(c-u_{2}\right)}{4}, & \text { if } 0<\rho<\rho^{0} \\
\frac{(1-\rho)\left(a+\Delta a+k_{s} \sigma\right)-\left(\alpha_{1}-\beta\right)\left(c-u_{2}\right)}{4}, & \text { if } \rho^{0} \leq \rho<1\end{cases} \\
& \overline{D_{d}}= \begin{cases}\frac{\left[2 \alpha_{1}\left(2 \alpha_{1}^{2}-3 \alpha_{1} \beta+2 \alpha_{1} \alpha_{2}-\beta^{2}\right)-\left(6 \alpha_{1}^{2}-9 \alpha_{1}^{2} \beta+4 \alpha_{1}^{3}+\beta^{3}-2 \alpha_{1} \alpha_{2} \rho\right)(1-\rho)\right](a+\Delta a)}{4 \alpha_{1} \gamma_{3}}- \\
\frac{\left(\beta^{2}+\alpha_{1} \beta-2 \alpha_{1} \alpha_{2}\right) \gamma_{2} k_{s} \sigma}{4 \alpha_{1} \gamma_{3}}+\frac{\left(\beta^{2}+\alpha_{1} \beta-2 \alpha_{1} \alpha_{2}\right)\left(c-u_{2}\right)}{4 \alpha_{1}}, & \text { if } 0<\rho<\rho^{0} \\
\frac{\left(\beta+2 \alpha_{1} \rho-\beta \rho\right)\left(a+\Delta a+k_{s} \sigma\right)+\left(\beta^{2}+\alpha_{1} \beta-2 \alpha_{1} \alpha_{2}\right)\left(c-u_{2}\right)}{4 \alpha_{1}}, & \text { if } \rho^{0} \leq \rho<1\end{cases} \\
& \bar{Q}=\bar{D}=\left\{\begin{array}{lr}
\frac{\gamma_{2}\left(a+\Delta a+k_{s} \sigma\right)-\gamma_{3}\left(c+u_{1}\right)}{4 \alpha_{1}}, & \text { if } \Delta a \geq \psi u_{1} \\
\frac{\gamma_{2}\left(a+k_{s} \sigma\right)-\gamma_{3} c}{4 \alpha_{1}}, & \text { if }-\psi u_{2}<\Delta a<\psi u_{1} \\
\frac{\gamma_{2}\left(a+\Delta a+k_{s} \sigma\right)-\gamma_{3}\left(c-u_{2}\right)}{4 \alpha_{1}}, & \text { if } \Delta a \leq-\psi u_{2}
\end{array}\right.
\end{aligned}
$$

Theorem 9 reveals that the demand and the disruption volume of a dual-channel supply chain under decentralization are related to the market shares of the different channels when market demand disruption occurs. The different market share of the two channels will lead to different demands under the given demand disruption. When the market share of the two channels is the same, the demand of each channel is different because of the different scales of demand disruption. The optimum output of the whole supply chain is also affected by the scale of demand disruption. When $\Delta a$ fluctuates within the range of $\left(-\psi u_{2}, \psi u_{1}\right)$, the optimum decisions are the same for the dual-channel supply chain. When $\Delta a$ is beyond the specified range, the optimum decisions are different.

By solving the first derivative of the risk aversion coefficient $k_{s}$ in price, sales volume and total output of the system in Theorems 8 and 9 , it is easy to determine that the first derivatives of the risk aversion coefficient of price are all less than 0 . The first derivatives of the risk aversion coefficient of sales volume are all higher than 0 . Conclusion 3 can be obtained by combining the variables in Theorems 6 and 7 and the relationship of $k_{s}$.

Conclusion 3 Regardless of the market share of the two channels and the degree of demand disruption, the higher the risk aversion coefficient of supplier is, the lower the price 
is. The relationship between the optimum sales volume and optimum total output is opposite to the risk aversion coefficient of supplier.

\subsection{The Comparison of Decision before and after the Disruption}

Theorem 10 can be obtained by combining Theorems 7 and 9 and comparing the relationship of the two channels' sales volume before and after the disruption.

Theorem 10 The relationship between the two channels' sales volume in a dual-channel supply chain which is led by supplier before and after the demand disruption is

When $\Delta a \geq \psi u_{1}$ :

$$
\begin{aligned}
& \overline{D_{r}}= \begin{cases}D_{r}^{\times}+\frac{\left[\gamma_{4}(1-\rho)-2 \alpha_{1}\left(\alpha_{1}-\beta\right)\right] \Delta a}{4 \gamma_{3}}-\frac{\left(\alpha_{1}-\beta\right) u_{1}}{4}, & \text { if } 0<\rho<\rho^{0} \\
D_{r}^{\times}+\frac{(1-\rho) \Delta a}{4}-\frac{\left(\alpha_{1}-\beta\right) u_{1}}{4}, & \text { if } \rho^{0} \leq \rho<1\end{cases} \\
& \overline{D_{d}}= \begin{cases}\frac{\left(\beta^{2}+\alpha_{1} \beta-2 \alpha_{1} \alpha_{2}\right) u_{1}}{4 \alpha_{1}}, & \text { if } 0<\rho<\rho^{0} \\
D_{d}^{\times}+\frac{\left[\alpha_{1}\left(\alpha_{1}^{2}-\beta^{2}+\gamma_{4}\right)-\left(6 \alpha_{1}^{2} \alpha_{2}-9 \alpha_{1}^{2} \beta+4 \alpha_{1}^{3}+\beta^{3}-2 \alpha_{1} \alpha_{2} \beta\right)(1-\rho)\right] \Delta a}{4 \alpha_{1} \gamma_{3}}+ \\
D_{d}^{\times}+\frac{\left(\beta+2 \alpha_{1} \rho-\beta \rho\right) \Delta a+\left(\beta^{2}+\alpha_{1} \beta-2 \alpha_{1} \alpha_{2}\right) u_{1}}{4 \alpha_{1}}, & \text { if } \rho^{0} \leq \rho<1\end{cases}
\end{aligned}
$$

When $-\psi u_{2}<\Delta a<\psi u_{1}$ :

$$
\begin{aligned}
& \overline{D_{r}}= \begin{cases}D_{r}^{\times}-\frac{\gamma_{1} \alpha_{1} \Delta a}{\gamma_{3}}, & \text { if } 0<\rho<\rho^{0} \\
D_{r}^{\times}-\frac{\gamma_{1} \alpha_{1} \Delta a}{2 \gamma_{3}}, & \text { if } \rho^{0} \leq \rho<1\end{cases} \\
& \overline{D_{d}}= \begin{cases}D_{d}^{\times}+\frac{\gamma_{1} \alpha_{1} \Delta a}{\gamma_{3}}, & \text { if } 0<\rho<\rho^{0} \\
D_{d}^{\times}+\frac{\gamma_{1} \alpha_{1} \Delta a}{2 \gamma_{3}}, & \text { if } \rho^{0} \leq \rho<1\end{cases}
\end{aligned}
$$

When $\Delta a \leq-\psi u_{2}$ :

$$
\overline{D_{r}}= \begin{cases}D_{r}^{\times}+\frac{\left[\gamma_{4}(1-\rho)-2 \alpha_{1}\left(\alpha_{1}-\beta\right)\right] \Delta a}{4 \gamma_{3}}+\frac{\left(\alpha_{1}-\beta\right) u_{2}}{4}, & \text { if } 0<\rho<\rho^{0} \\ D_{r}^{\times}+\frac{(1-\rho) \Delta a+\left(\alpha_{1}-\beta\right) u_{2}}{4}, & \text { if } \rho^{0} \leq \rho<1\end{cases}
$$




$$
\overline{D_{d}}= \begin{cases}D_{d}^{\times}+\frac{\left[\alpha_{1}\left(\alpha_{1}^{2}-\beta^{2}+\gamma_{4}\right)-\left(6 \alpha_{1}^{2} \alpha_{2}-9 \alpha_{1}^{2} \beta+4 \alpha_{1}^{3}+\beta^{3}-2 \alpha_{1} \alpha_{2} \beta\right)(1-\rho)\right] \Delta a}{4 \alpha_{1} \gamma_{3}}- \\ \left(\beta^{2}+\alpha_{1} \beta-2 \alpha_{1} \alpha_{2}\right) u_{2} \\ 4 \alpha_{1} & \text { if } 0<\rho<\rho^{0} \\ D_{d}^{\times}+\frac{\left(\beta+2 \alpha_{1} \rho-\beta \rho\right) \Delta a-\left(\beta^{2}+\alpha_{1} \beta-2 \alpha_{1} \alpha_{2}\right) u_{2}}{4 \alpha_{1}}, & \text { if } \rho^{0} \leq \rho<1\end{cases}
$$

According to Theorem 10, the adjusting output of the two channels is a linear function of $\Delta a$ in the same scale of disruption and market share. However, their sales volume is different as the change rate of $\Delta a$ is different. By comparing the pricing strategy of the supply chain before and after the demand disruption, the relationship between the pricing strategy and variable without disruption is also found to be a linear function of $\Delta a$. More details regarding it will not be shown because of the limited paragraph.

Proposition 2 can be obtained by comparing the change of different sales volume in different channels and scales of disruption.

Proposition 2 When the demand disruption is within the range of $\left(-\psi u_{2}, \psi u_{1}\right)$, the sales volume in the two channels have the same stability. When the demand disruption is beyond the range, the stability of sales volume is relevant to their market share.

The proof can be seen in Appendix 2.

Theorem 11 can be obtained according to the optimum output of the supply chain system in two conditions from Theorems 7 and 9.

Theorem 11 The relationship between the optimum output after the disruption and the original output before the disruption is

$$
\bar{Q}=\left\{\begin{array}{lr}
Q^{\times}+\frac{\gamma_{2} \Delta a-\gamma_{3} u_{1}}{4 \alpha_{1}}, & \text { if } \Delta a \geq \psi u_{1} \\
Q^{\times}, & \text {if }-\psi u_{2}<\Delta a<\psi u_{1} \\
Q^{\times}+\frac{\gamma_{2} \Delta a+\gamma_{3} u_{2}}{4 \alpha_{1}}, & \text { if } \Delta a \leq-\psi u_{2}
\end{array}\right.
$$

Theorem 11 suggests that $\left(-\psi u_{2}, \psi u_{1}\right)$ is the robust point interval of the optimum output under decentralization. When the demand is within this range, the supply system does not need to adjust to the production plan. When the demand is beyond this range, the supply chain should be changed. When $\Delta a \geq \psi u_{1}$, the output that will be adjusted can be regarded 
as a new market, wherein the market size is $\Delta a$ and the marginal cost of production is $u_{1}$. When $\Delta a \leq-\psi u_{2}$, the output that will be adjusted can be regarded as a new market, wherein the market size is $\Delta a$ and the marginal cost of production is $-u_{2}$. Moreover, the output to be adjusted is not relevant to the leader's risk-averse attitude, but is only affected by the parameters of the supply chain.

Proposition 3 When $0<\rho<\rho^{0}$, the original optimum output has higher robustness under centralization than under decentralization, whereas $\rho^{0}<\rho<1$ exhibits the opposite.

Proof In comparing the range of the original optimum output under decentralization and that under centralization,

$$
\chi=\left(\alpha_{1}+\alpha_{2}-2 \beta\right)-\frac{\alpha_{1}^{2}+2 \alpha_{1} \alpha_{2}-2 \alpha_{1} \beta-\beta^{2}}{\alpha_{1}+\beta+\alpha_{1} \rho-\beta \rho}=\frac{\left(\alpha_{1}-\beta\right)\left[\left(\beta-\alpha_{2}\right)+\left(\alpha_{1}+\alpha_{2}-2 \beta\right) \rho\right]}{\alpha_{1}+\beta+\alpha_{1} \rho-\beta \rho}
$$

It's easy to prove that when $0<\rho<\rho^{0}, \chi<0$, the range under decentralization is wider. When $\rho^{0}<\rho<1, \chi>0$, the range under centralization is wider. Thus, Proposition 3 is demonstrated.

\section{Numerical Analysis}

\subsection{Dual-channel Supply Chain Decisions in a Centralized Decision-making Model}

Based on relevant literature [see 6, 7, 24, 25], the parameters of the model are consistent with the model consumptions. In this study, we set $\tilde{a} \sim N\left(100,20^{2}\right), \alpha_{1}=3, \alpha_{2}=5, \beta=1$, $\rho=0.4, c=4, u_{1}=u_{2}=2, k>0$ for the numerical analysis.

These equations indicate that the demarcations of the decision-making variables are $\Delta a=\left(\alpha_{1}+\alpha_{2}-2 \beta\right) u_{1}$ and $\Delta a=-\left(\alpha_{1}+\alpha_{2}-2 \beta\right) u_{2}$. The simulation data are substituted into these equations to obtain demarcation point $\Delta a= \pm 12$ and robust interval $(-12,12)$.

(1) Effects of $\Delta a$ and $k$ on the decision-making variables under centralized decision

We set $\Delta a=-25,-10,0,10,25$ to ensure that market demand disruption is within and outside the robust region. We can then conclude on the relationship among optimal price, 
optimal sales volume within two channels, and risk aversion coefficient under stable and perturbation environments. Our conclusion is based on other data in the supply chain, as shown in Figure 2 (the range of different variables is adjusted to easily distinguish the line in the figure). $\Delta a=0$ denotes the value of each variable in a stable environment.

Figure 2 indicates that the value of optimal pricing is inversely proportional to the risk aversion coefficient of the system under stable and perturbation environments. By contrast, the optimal sales volume within the two channels is positively related to the risk aversion coefficient, which is consistent with Conclusion 1. The parallel relationship between the lines in the figure implies that the fluctuation in the variables caused by demand disruption is unaffected by the risk aversion coefficient. The variables that the system needs to adjust are linearly correlated with $\Delta a$ when demand fluctuation occurs. We can further verify the correctness of Conclusion 1 from this finding. Figure 2 shows that great disturbance amplitude leads to high optimal sales price and optimal sales volume in the traditional distribution channel with the same risk aversion coefficient. When the degree of demand disruption is relatively large, the optimal sales volume of the direct channel is smaller than the demand fluctuation range. This finding is attributed to the robustness of optimal total output.
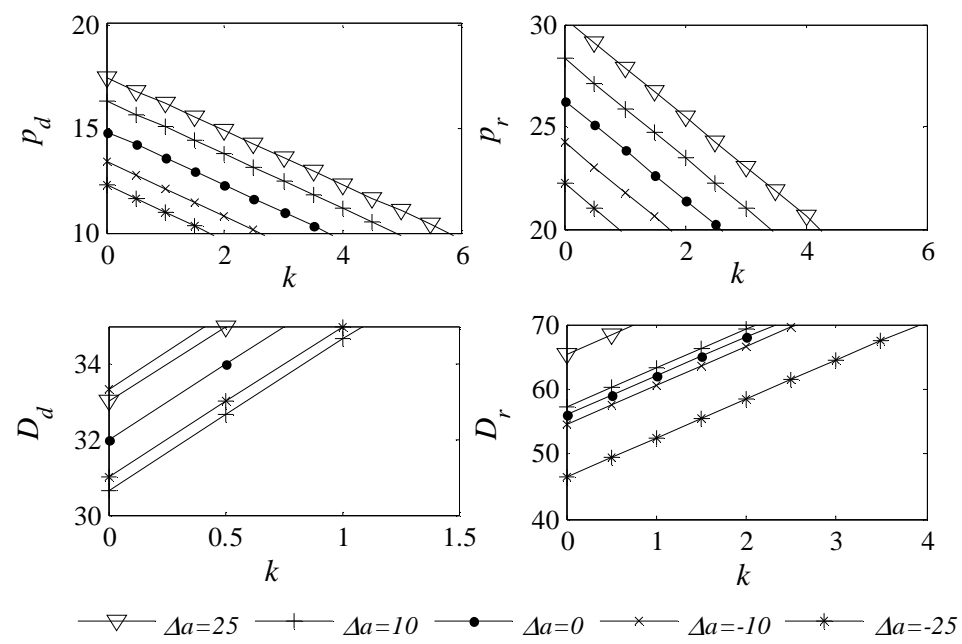

Fig. 2. Effects of $\Delta a$ and $k$ on the decision-making variables under centralized decision

(2) Effects of $\Delta a$ and $k$ on the optimal output under centralized decision

The simulation data are substituted into the optimal total output obtained by Theorems 1 and 5. The demand disruption $\Delta a \in(-25,25)$ and the risk aversion coefficient $k=2,5,8,10$ 
are set. We can then obtain the relationship between the optimal output and the market demand disruption $\Delta a$ and risk aversion coefficient $k$, as shown in Figure 3.

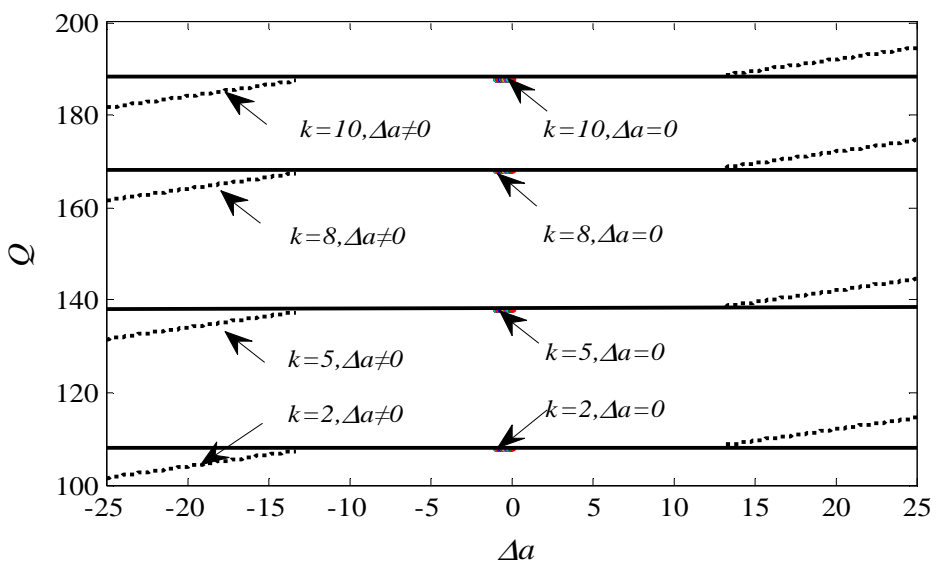

Fig. 3. Effects of $\Delta a$ and $k$ on the optimal output under centralized decision

As shown in Theorem 5 and Conclusion 2, Figure 3 indicates that the optimal production volume is robust in the centralized decision-making system. When the demand disruption scale is within the robust range $(-12,12)$, the optimal total production is equal to the production without disruption. High market demand results in high optimal output outside the robust range. Regardless of demand disruption, the optimal output has a positive correlation with the risk aversion coefficient, which is consistent with Conclusion 1.

\subsection{Dual-channel Supply Chain Decisions in the Decentralized Decision-making Model}

Similar to the preceding condition, we set $\tilde{a} \sim N\left(100,20^{2}\right), \alpha_{1}=3, \alpha_{2}=5, \beta=1$, $\rho=0.4, c=4, u_{1}=u_{2}=2$, and $k_{s}>0$ for the numerical analysis.

In a dual-channel supply chain where the risk-averse supplier acts as the leader, market share $\rho^{0}=\frac{\alpha_{2}-\beta}{\alpha_{1}+\alpha_{2}-2 \beta}$, market demand disruption $\Delta a=\psi u_{1}$, and $\Delta a=-\psi u_{2}$ are the demarcations of the decision-making variables. The simulation data are substituted into the aforementioned equations. We can then obtain the demarcation point $\rho^{0}=2 / 3$ and the robust interval $(-40 / 3,40 / 3)$.

(1) Effects of $\Delta a$ and $k_{s}$ on the decision-making variables under decentralized decision 
We set $\Delta a=-25,-10,0,10,25$ to ensure that market demand disruption is within and outside the robust region. We can then obtain the relationship among optimal price, optimal sales volume within two channels, and risk aversion coefficient under stable and perturbation environments based on the simulation data, as shown in Figure 4.
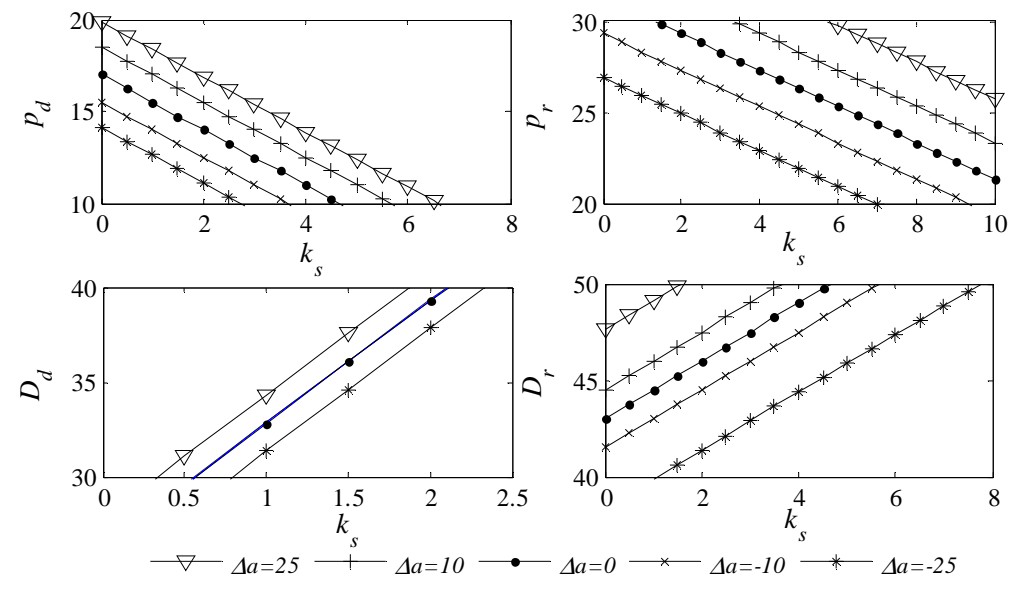

Fig. 4. Effects of $\Delta a$ and $k_{s}$ on the decision-making variables under decentralized decision

Figure 4 indicates that the optimal pricing value is inversely proportional to the risk aversion coefficient of the system under stable and perturbation environments. By contrast, the optimal sales volume within the two channels is positively related to the risk aversion coefficient. This finding means that the high risk aversion coefficient of leaders leads to low prices and high sales volumes in the two channels regardless of the external environment changes. This finding is consistent with Conclusion 3.

Under the same risk aversion coefficient, the higher the market demand is, the greater the prices in the two channels and the sales volume in the distribution channel are. This finding is consistent with reality. Figure 4 also indicates that the demand for online direct sales channels when $\Delta a= \pm 10$ is close to the demand when $\Delta a=0$. This finding means that the optimal sales in the perturbation environment is close to the optimal sales in the stable environment when the sales volume in the direct channels accounts for $40 \%$ and the market demand disruption is in the robust range.

(2) Effects of $\Delta a$ and $k_{s}$ on the optimal output under decentralized decision

The simulation data are substituted into the optimal total output obtained by Theorems 7 
and 8. Risk aversion coefficients $k_{s}=2,5,8,10$ are then set. We can then obtain the effects of market demand disruption $\Delta a$ and risk aversion coefficient $k_{s}$ on the optimal output, as shown in Figure 5.

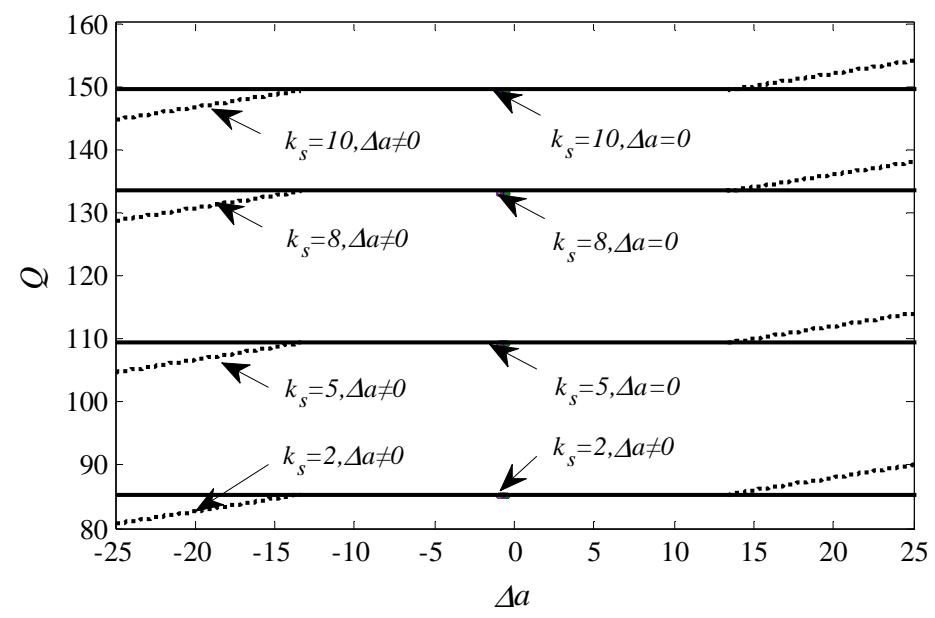

Fig. 5. Effects of $\Delta a$ and $k_{s}$ on the optimal output under decentralized decision.

Figure 5 verifies the robustness of the optimal output in the decentralized decision-making supply chain under demand disruption. When the intensity of the disturbance is within the robust range $(-40 / 3,40 / 3)$, the optimal output in the perturbation environment is similar to that in the stable environment. The optimal output needs should be adjusted based on that in the stable environment when disturbance intensity is beyond the robust range. When market demand disruption is higher than the upper limit of the robust region $40 / 3$, the optimal output is higher than the original output. The optimal output is smaller than the original output when the market demand is less than the lower limit of the robust region $-40 / 3$. Great disturbance intensity leads to high output that needs to be adjusted. This finding is consistent with Theorem 11.

Figure 5 shows that great risk aversion coefficient of the supplier results in optimal total output of the supply chain under the same market demand disruption. This finding is consistent with Conclusion 3. The optimal total output is positively related to the risk aversion coefficient, which means that high optimal output is obtained when the leader 
significantly avoids risk.

\section{Conclusions}

This paper considers two supply chains based on previous research, namely, risk-averse dual-channel supply chain under centralization and dual-channel supply chain under decentralization with a risk-averse supplier. The optimum price and production decisions of the supply chain with and without demand disruption are discussed. The influences of risk-averse attitude, channel structure, and scale of the demand disruption on supply chain decisions are also examined.

Innovatively, this paper considers the optimum strategy and provides a simple determination method of a risk-averse dual-channel supply chain before and after demand disruption. This method includes the addition of the linear function of demand disruption based on the optimum strategy without disruption to avoid the effect of risk aversion coefficient. This study suggests the robust interval of the optimum output in two strategies. The system should adjust the production plan when the demand disruption is within the range. This study also considers the effect of demand disruption to the sales volume of a risk-averse dual-channel supply chain and emphasizes on the stability of the two channels when disrupted. This finding is beneficial for managers because they can adjust the sales volume of the two channels of the current situation and avoid the situation wherein demand exceeds supply or supply exceeds demand. This research can supplement previous research and can provide specific academic significance and actual value. However, this paper has particular limitations. For example, the situation in which the market size has less influence on decisions than on risk attitude is not considered. Moreover, the effect of market scale is assumed to be stronger than the attitude of risk when making a decision. Thus, the detailed factors that have been ignored have simplified the current research and could be the prospective subjects for study.

\section{Acknowledgments}

This work was supported by Program (71172075) and Major International (Regional) Joint Research Project (71420107024) of Natural Science Foundation of China, Guangdong 
Natural Science Foundation (2016A030313485), Guangdong Soft Science Research Project (2015A070704005), Guangdong "12th Five-Year" Philosophy and Social Sciences Planning Project (GD15CGL15), Guangdong Science and Technology Planning Project (2013B040500007, 2013B040200057), and Fundamental Research Funds for the Central Universities (2015KXKYJ02).

\section{References}

[1]Qi X, Bard JF, Yu G. Supply chain coordination with demand disruptions. Omega 2003; 32: 301-312.

[2]Khokhar SG, Min Q, Su C. Bird flu (H7N9) outbreak and its implications on the supply chain of poultry meat in China. J Appl Poult Res 2015; 24(2): 215-221.

[3]Clausen J, Larsen A, Larsen J, Rezanova NJ. Disruption management in the airline industry - concepts, models and methods. Comput Operat Res 2010; 37(5): 809-821.

[4]Hua G, Wang S, Cheng TCE. Price and lead time decisions in dual-channel supply chains. Euro J Operat Res 2010; 205(1): 113-126.

[5]Cai GG. Channel selection and coordination in dual-channel supply chains. J Retailing 2010; 86(1): $22-36$.

[6]Yan R, Ghose S. Forecast information and traditional retailer performance in a dual-channel competitive market. J Bus Res 2010; 63(1): 77-83.

[7]Tsay AA, Agrawal N. Channel conflict and coordination in the e-commerce age. Product Operat Manage 2004; 13(1): 93-110.

[8]Zhang R, Liu B, Wang WL. Pricing decisions in a dual channels system with different power structures. Econ Model 2012; 29(2): 523-533.

[9]Xu H, Liu ZZ, Zhang SH. A strategic analysis of dual-channel supply chain design with price and delivery lead time considerations. Int J Prod Econ 2012; 139: 654-663.

[10]Dan B, Xu GY, Liu C. Pricing policies in a dual-channel supply chain with retail services. Int J Prod Econ 2012; 139(1): 312-320.

[11]Yan R, Pei Z. Retail services and firm Profit in a dual-channel market. J Retailing Consum Serv 2009; (16): 306-314.

[12]Zhang F, Ma J. Research on the complex features about a dual-channel supply chain with a fair caring retailer. Commun Nonlinear Sci Numer Simulat 2016; 30: 151-167.

[13]Yao DQ, Liu JJ. Competitive pricing of mixed retail and e-tail distribution channels. Omega 2005; 33(3): 
235-247.

[14]Xiao T, Yu G, Sheng Z, Xia Y. Coordination of a supply chain with one-manufacturer and two-retailers under demand promotion and disruption management decisions. Ann Operat Res 2005; 135(1): 87-109.

[15]Huang C, Yu G, Wang S, Wang X. Disruption management for supply chain coordination with exponential demand function. Acta Math Sci 2006; 26(4): 655-669.

[16]Zhang W, Fu J, Li H, Xu W. Coordination of supply chain with a revenue-sharing contract under demand disruptions when retailers compete. Int J Prod Econ 2012; 138(1): 67-75.

[17]Xiao TJ, Qi XT, Yu G. Coordination of supply chain after demand disruptions when retailers compete. Int J Prod Econ 2007: 109(1): 162-179.

[18]Cao EB, Wan C, Lai MY. Coordination of a supply chain with one manufacturer and multiple competing retailers under simultaneous demand and cost disruptions. Int J Prod Econ 2013; 141(1): $425-433$.

[19]Ma J, Xie L. Study on the complexity pricing game and coordination of the duopoly air conditioner market with disturbance demand. Commun Nonlinear Sci Numer Simulat 2016; 30: 99-113.

[20]Chen K, Zhuang P. Disruption management for a dominant retailer with constant demand-stimulating service cost. Comput Ind Eng 2011; 61(4): 936-946.

[21]Huang S, Yang C, Zhang X. Pricing and production decisions in dual-channel supply chains with demand disruptions. Comput Ind Eng 2012; 62(1): 70-83.

[22]Brown AO, Tang CS. The impact of alternative performance measures on single-period inventory policy. J Ind Manage Optim 2006; 2(3): 297-318.

[23]Choi TM, Li D, Yan H. Mean - variance analysis of a single supplier and retailer supply chain under a returns policy. Euro J Operat Res 2008; 184(1): 356-376.

[24]Xiao T, Choi TM. Purchasing choices and channel structure strategies for a two-echelon-system with risk-averse players. Int J Prod Econ 2009; 120(1): 54-65.

[25]Xu GY, Dan B, Zhang XM, Liu C. Coordinating a dual-channel supply chain with risk-averse under a two-way revenue sharing contract. Int J Prod Econ 2014; (147): 171-179.

[26]Liu M, Cao E, Salifou CK. Pricing strategies of a dual-channel supply chain with risk aversion. Transport Res Part E 2016; 90: 108-120.

[27]Markowitz H. Portfolio selection. The Journal of Finance 1952; 7(1): 77-91.

[28]Bannister H, Goldys B, Penev S, Wu W. Multiperiod mean-standard-deviation time consistent 
portfolio selection. Automatica 2016; 73: 15-26.

\section{Appendix 1}

Proof: We assume that the variation coefficient of the demand disruption within the range of $\left(-\left(\alpha_{1}+\alpha_{2}-2 \beta\right) u_{2},\left(\alpha_{1}+\alpha_{2}-2 \beta\right) u_{1}\right)$ in traditional distribution channel and online direct selling channel is $\theta_{1}$ and $\theta_{2}$. The variation coefficient of the demand disruption beyond the range of $\left(-\left(\alpha_{1}+\alpha_{2}-2 \beta\right) u_{2},\left(\alpha_{1}+\alpha_{2}-2 \beta\right) u_{1}\right)$ in traditional distribution channel and online direct selling channel is $\theta_{3}$ and $\theta_{4}$. Thus, $\theta_{1}=\theta_{2}=\left|\frac{\gamma_{1}}{2\left(\alpha_{1}+\alpha_{2}-2 \beta\right)}\right|, \theta_{3}=\frac{1-\rho}{2}$, $\theta_{4}=\frac{\rho}{2}$

1) When $-\left(\alpha_{1}+\alpha_{2}-2 \beta\right) u_{2}<\Delta a<\left(\alpha_{1}+\alpha_{2}-2 \beta\right) u_{1}$, $\theta_{1}-\theta_{2}=0$

The effect of the demand disruption namely the stability of the two channels is the same in the above fluctuation interval.

2) When $\Delta a \geq\left(\alpha_{1}+\alpha_{2}-2 \beta\right) u_{1}$ or $\Delta a \leq-\left(\alpha_{1}+\alpha_{2}-2 \beta\right) u_{2}, \quad \theta_{3}-\theta_{4}=\frac{(1-\rho)}{2}-\frac{\rho}{2}=\frac{1-2 \rho}{2}$. So when $\rho>\frac{1}{2}, \theta_{3}<\theta_{4}$. When $\rho=\frac{1}{2}, \theta_{3}=\theta_{4}$. When $\rho<\frac{1}{2}, \theta_{3}>\theta_{4}$.

When range of demand fluctuation is large, the channel that has a bigger market share will have worse stability. When two of the channels have equal market share, their stability are the same.

3) For the traditional distribution channel:

a) When $0<\rho<\rho^{0}\left(\rho^{0}=\frac{\alpha_{2}-\beta}{\alpha_{1}+\alpha_{2}-2 \beta}\right), \quad \gamma_{1}<0$. That is 
$\theta_{1}=\frac{\alpha_{2}-\beta-\alpha_{1} \rho-\alpha_{2} \rho+2 \beta \rho}{2\left(\alpha_{1}+\alpha_{2}-2 \beta\right)}$

As $\theta_{1}-\theta_{3}=\frac{\alpha_{2}-\beta-\alpha_{1} \rho-\alpha_{2} \rho+2 \beta \rho}{2\left(\alpha_{1}+\alpha_{2}-2 \beta\right)}-\frac{1-\rho}{2}=\frac{\beta-\alpha_{1}}{2\left(\alpha_{1}+\alpha_{2}-2 \beta\right)}<0, \theta_{1}<\theta_{3}$.

b) When $\rho^{0} \leq \rho<1, \quad \gamma_{1}>0$. That is, $\theta_{1}=\frac{\beta-\alpha_{2}+\alpha_{1} \rho+\alpha_{2} \rho-2 \beta \rho}{2\left(\alpha_{1}+\alpha_{2}-2 \beta\right)}$.

At this case,

$\theta_{1}-\theta_{3}=\frac{\beta-\alpha_{2}+\alpha_{1} \rho+\alpha_{2} \rho-2 \beta \rho}{2\left(\alpha_{1}+\alpha_{2}-2 \beta\right)}-\frac{1-\rho}{2}=\frac{2\left(\alpha_{1}+\alpha_{2}-2 \beta\right) \rho-\left(\alpha_{1}+2 \alpha_{2}-3 \beta\right)}{2\left(\alpha_{1}+\alpha_{2}-2 \beta\right)}$.

So when $\rho^{0} \leq \rho<\frac{\alpha_{1}+2 \alpha_{2}-3 \beta}{2\left(\alpha_{1}+\alpha_{2}-2 \beta\right)}, \quad \theta_{1}<\theta_{3}$. When $\frac{\alpha_{1}+2 \alpha_{2}-3 \beta}{2\left(\alpha_{1}+\alpha_{2}-2 \beta\right)}<\rho<1, \quad \theta_{1}>\theta_{3}$.

When $\rho=\frac{\alpha_{1}+2 \alpha_{2}-3 \beta}{2\left(\alpha_{1}+\alpha_{2}-2 \beta\right)}, \quad \theta_{1}=\theta_{3}$.

c) Combined the above two situation, when $0<\rho<\frac{\alpha_{1}+2 \alpha_{2}-3 \beta}{2\left(\alpha_{1}+\alpha_{2}-2 \beta\right)}, \theta_{1}<\theta_{3}$. When $\frac{\alpha_{1}+2 \alpha_{2}-3 \beta}{2\left(\alpha_{1}+\alpha_{2}-2 \beta\right)}<\rho<1, \theta_{1}>\theta_{3}$. When $\rho=\frac{\alpha_{1}+2 \alpha_{2}-3 \beta}{2\left(\alpha_{1}+\alpha_{2}-2 \beta\right)}, \theta_{1}=\theta_{3}$.

So the lager the market share of the traditional distribution channel and the scale of demand disruption are, the worse the stability is. On the contrary, the smaller the market share of the traditional distribution channel is and the larger the scale of demand disruption is, the better the stability is.

4) For the online direct selling channel:

a) When $0<\rho<\rho^{0}, \theta_{2}=\frac{\alpha_{2}-\beta-\alpha_{1} \rho-\alpha_{2} \rho+2 \beta \rho}{2\left(\alpha_{1}+\alpha_{2}-2 \beta\right)}$,

$\theta_{2}-\theta_{4}=\frac{\alpha_{2}-\beta-\alpha_{1} \rho-\alpha_{2} \rho+2 \beta \rho}{2\left(\alpha_{1}+\alpha_{2}-2 \beta\right)}-\frac{\rho}{2}=\frac{\alpha_{2}-\beta-2\left(\alpha_{1}+\alpha_{2}-2 \beta\right) \rho}{2\left(\alpha_{1}+\alpha_{2}-2 \beta\right)}$.

So, when $0<\rho<\frac{\alpha_{2}-\beta}{2\left(\alpha_{1}+\alpha_{2}-2 \beta\right)}, \quad \theta_{2}>\theta_{4}$. When $\frac{\alpha_{2}-\beta}{2\left(\alpha_{1}+\alpha_{2}-2 \beta\right)}<\rho<\rho^{0}, \theta_{2}<\theta_{4}$. 
When $\rho=\frac{\alpha_{2}-\beta}{2\left(\alpha_{1}+\alpha_{2}-2 \beta\right)}, \theta_{2}=\theta_{4}$.

b) When $\rho^{0} \leq \rho<1, \quad \theta_{2}=\frac{\beta-\alpha_{2}+\alpha_{1} \rho+\alpha_{2} \rho-2 \beta \rho}{2\left(\alpha_{1}+\alpha_{2}-2 \beta\right)}$,

$\theta_{2}-\theta_{4}=\frac{\beta-\alpha_{2}+\alpha_{1} \rho+\alpha_{2} \rho-2 \beta \rho}{2\left(\alpha_{1}+\alpha_{2}-2 \beta\right)}-\frac{\rho}{2}=\frac{\beta-\alpha_{2}}{2\left(\alpha_{1}+\alpha_{2}-2 \beta\right)}<0$. That is $\theta_{2}<\theta_{4}$.

c) Combined the above two situation, when $0<\rho<\frac{\alpha_{2}-\beta}{2\left(\alpha_{1}+\alpha_{2}-2 \beta\right)}, \theta_{2}>\theta_{4}$. When $\frac{\alpha_{2}-\beta}{2\left(\alpha_{1}+\alpha_{2}-2 \beta\right)}<\rho<1, \theta_{2}<\theta_{4}$. When $\rho=\frac{\alpha_{2}-\beta}{2\left(\alpha_{1}+\alpha_{2}-2 \beta\right)}, \quad \theta_{2}=\theta_{4}$.

Thus, the smaller the market share of the online direct selling channel is and the larger the scale of disruption is, the better the stability is. And it performances the opposite when the market share is large.

\section{Appendix 2}

Proof When $-\psi u_{2}<\Delta a<\psi u_{1}$,

(1) If $0<\rho<\rho^{0},\left|\frac{\partial\left(\overline{D_{r}}-D_{r}^{\times}\right)}{\partial \Delta a}\right|=\left|-\frac{\gamma_{1} \alpha_{1}}{\gamma_{3}}\right|=\left|\frac{\gamma_{1} \alpha_{1}}{\gamma_{3}}\right|=\left|\frac{\partial\left(\overline{D_{d}}-D_{d}^{\times}\right)}{\partial \Delta a}\right|$.

(2) If $\rho^{0} \leq \rho<1,\left|\frac{\partial\left(\overline{D_{r}}-D_{r}^{\times}\right)}{\partial \Delta a}\right|=\left|-\frac{\gamma_{1} \alpha_{1}}{2 \gamma_{3}}\right|=\left|\frac{\gamma_{1} \alpha_{1}}{2 \gamma_{3}}\right|=\left|\frac{\partial\left(\overline{D_{d}}-D_{d}^{\times}\right)}{\partial \Delta a}\right|$.

That is, the two channels have the same stability of demand.

When $\Delta a \geq \psi u_{1}$ or $\Delta a \leq-\psi u_{2}$ :

(1) If $0<\rho<\rho^{0}$ :

The change rate of $\overline{D_{r}}$ is $\frac{\partial\left(\overline{D_{r}}-D_{r}^{\times}\right)}{\partial \Delta a}=\frac{\left[\gamma_{4}(1-\rho)-2 \alpha_{1}\left(\alpha_{1}-\beta\right)\right]}{4 \gamma_{3}}$.

The change rate of $\overline{D_{d}}$ is

$\frac{\partial\left(\overline{D_{d}}-D_{d}^{\times}\right)}{\partial \Delta a}=\frac{\left[\alpha_{1}\left(\alpha_{1}^{2}-\beta^{2}+\gamma_{4}\right)-\left(6 \alpha_{1}^{2} \alpha_{2}-9 \alpha_{1}^{2} \beta+4 \alpha_{1}^{3}+\beta^{3}-2 \alpha_{1} \alpha_{2} \beta\right)(1-\rho)\right]}{4 \alpha_{1} \gamma_{3}}$. 
Let $\frac{\partial\left(\overline{D_{r}}-D_{r}^{\times}\right)}{\partial \Delta a}-\frac{\partial\left(\overline{D_{d}}-D_{d}^{\times}\right)}{\partial \Delta a}=0$, so that

$$
\rho^{*}=\frac{\alpha_{1}^{3}-7 \alpha_{1}^{2} \beta+6 \alpha_{1}^{2} \alpha_{2}+\alpha_{1} \beta^{2}-2 \alpha_{1} \alpha_{2} \beta+\beta^{3}}{7 \alpha_{1}^{3}-15 \alpha_{1}^{2} \beta+10 \alpha_{1}^{2} \alpha_{2}-\alpha_{1} \beta^{2}-2 \alpha_{1} \alpha_{2} \beta+\beta^{3}}
$$

For convenient analysis, we assume that the price effect of the online direct selling channel is greater than that of the traditional distribution channel. That is,

$$
\begin{aligned}
\alpha_{2}>\alpha_{1} & >\beta . \\
\rho^{0}-\rho^{*} & =\frac{4 \alpha_{1}\left(\alpha_{1} \alpha_{2}-\beta^{2}\right)\left(\alpha_{2}-\beta\right)-\left(\alpha_{1}+\beta\right)\left(\alpha_{1}-\beta\right)^{3}}{\left[\left(7 \alpha_{1}^{2}+2 \alpha_{1} \alpha_{2}-\beta^{2}\right)\left(\alpha_{1}-\beta\right)+8 \alpha_{1}^{2}\left(\alpha_{2}-\beta\right)\right]\left(\alpha_{1}+\alpha_{2}-2 \beta\right)} \\
& >\frac{4 \alpha_{1}\left(\alpha_{1} \alpha_{2}-\beta^{2}\right)\left(\alpha_{1}-\beta\right)-2 \alpha_{1}\left(\alpha_{1}-\beta\right)^{3}}{\left[\left(7 \alpha_{1}^{2}+2 \alpha_{1} \alpha_{2}-\beta^{2}\right)\left(\alpha_{1}-\beta\right)+8 \alpha_{1}^{2}\left(\alpha_{2}-\beta\right)\right]\left(\alpha_{1}+\alpha_{2}-2 \beta\right)} \\
& =\frac{2 \alpha_{1}\left(\alpha_{1}-\beta\right)\left(2 \alpha_{1} \alpha_{2}-3 \beta^{2}-\alpha_{1}^{2}+2 \alpha_{1} \beta\right)}{\left[\left(7 \alpha_{1}^{2}+2 \alpha_{1} \alpha_{2}-\beta^{2}\right)\left(\alpha_{1}-\beta\right)+8 \alpha_{1}^{2}\left(\alpha_{2}-\beta\right)\right]\left(\alpha_{1}+\alpha_{2}-2 \beta\right)} \\
& >\frac{2 \alpha_{1}\left(\alpha_{1}-\beta\right)\left(2 \alpha_{1}^{2}-3 \beta^{2}-\alpha_{1}^{2}+2 \beta^{2}\right)}{\left[\left(7 \alpha_{1}^{2}+2 \alpha_{1} \alpha_{2}-\beta^{2}\right)\left(\alpha_{1}-\beta\right)+8 \alpha_{1}^{2}\left(\alpha_{2}-\beta\right)\right]\left(\alpha_{1}+\alpha_{2}-2 \beta\right)} \\
& =\frac{2 \alpha_{1}\left(\alpha_{1}-\beta\right)^{2}\left(\alpha_{1}+\beta\right)}{\left[\left(7 \alpha_{1}^{2}+2 \alpha_{1} \alpha_{2}-\beta^{2}\right)\left(\alpha_{1}-\beta\right)+8 \alpha_{1}^{2}\left(\alpha_{2}-\beta\right)\right]\left(\alpha_{1}+\alpha_{2}-2 \beta\right)} \\
& >0
\end{aligned}
$$

Thus, $\rho^{0}-\rho^{*}>0, \rho^{0}>\rho^{*}$.

When $0<\rho<\rho^{*}, \frac{\partial\left(\overline{D_{r}}-D_{r}^{\times}\right)}{\partial \Delta a}>\frac{\partial\left(\overline{D_{d}}-D_{d}^{\times}\right)}{\partial \Delta a}$. When $\rho=\rho^{*}, \frac{\partial\left(\overline{D_{r}}-D_{r}^{\times}\right)}{\partial \Delta a}=\frac{\partial\left(\overline{D_{d}}-D_{d}^{\times}\right)}{\partial \Delta a}$.

When $\rho^{*}<\rho<\rho^{0}, \frac{\partial\left(\overline{D_{r}}-D_{r}^{\times}\right)}{\partial \Delta a}<\frac{\partial\left(\overline{D_{d}}-D_{d}^{\times}\right)}{\partial \Delta a}$.

When the market share of the online direct selling channel is $0<\rho<\rho^{*}$, its stability is stronger than the traditional distribution channel. When $\rho^{*}<\rho<\rho^{0}$, the result is opposite. When $\rho=\rho^{*}$, the two channel have the same stability.

(2) If $\rho^{0} \leq \rho<1$ :

The change rate of $\overline{D_{r}}$ is $\frac{\partial\left(\overline{D_{r}}-D_{r}^{\times}\right)}{\partial \Delta a}=\frac{1-\rho}{4}$. 
The change rate of $\overline{D_{d}}$ is $\frac{\partial\left(\overline{D_{d}}-D_{d}^{\times}\right)}{\partial \Delta a}=\frac{\beta+2 \alpha_{1} \rho-\beta \rho}{4 \alpha_{1}}$.

Let $\frac{\partial\left(\overline{D_{r}}-D_{r}^{\times}\right)}{\partial \Delta a}-\frac{\partial\left(\overline{D_{d}}-D_{d}^{\times}\right)}{\partial \Delta a}=\frac{\alpha_{1}-\beta-\left(3 \alpha_{1}-\beta\right) \rho}{4 \alpha_{1}}=0$, so that $\rho^{\times}=\frac{\alpha_{1}-\beta}{3 \alpha_{1}-\beta}$.

As $\quad \rho^{0}-\rho^{\times}=\frac{\alpha_{2}-\beta}{\alpha_{1}+\alpha_{2}-2 \beta}-\frac{\alpha_{1}-\beta}{3 \alpha_{1}-\beta}=\frac{\left(\alpha_{1} \alpha_{2}-\beta^{2}\right)+\alpha_{1}\left(\alpha_{2}-\alpha_{1}\right)}{\left(\alpha_{1}+\alpha_{2}-2 \beta\right)\left(3 \alpha_{1}-\beta\right)}$, we assume that $\alpha_{2}>\alpha_{1}>\beta$, $\rho^{0}-\rho^{\times}>0, \quad \rho^{\times}<\rho^{0}$.

So when $\rho^{0} \leq \rho<1, \frac{\partial\left(\overline{D_{r}}-D_{r}^{\times}\right)}{\partial \Delta a}<\frac{\partial\left(\overline{D_{d}}-D_{d} \times\right)}{\partial \Delta a}$. That is, the stability of the direct selling channel is worse.

Combined with (1) and (2) we can find that when the scale of demand disruption is beyond the robust interval, the market share of the direct selling channel $\rho$ divides the market into two parts. When $0<\rho<\frac{\alpha_{1}^{3}-7 \alpha_{1}^{2} \beta+6 \alpha_{1}^{2} \alpha_{2}+\alpha_{1} \beta^{2}-2 \alpha_{1} \alpha_{2} \beta+\beta^{3}}{7 \alpha_{1}^{3}-15 \alpha_{1}^{2} \beta+10 \alpha_{1}^{2} \alpha_{2}-\alpha_{1} \beta^{2}-2 \alpha_{1} \alpha_{2} \beta+\beta^{3}}$, the traditional distributional channel is more affected by the demand disruption. When $\rho=\frac{\alpha_{1}^{3}-7 \alpha_{1}^{2} \beta+6 \alpha_{1}^{2} \alpha_{2}+\alpha_{1} \beta^{2}-2 \alpha_{1} \alpha_{2} \beta+\beta^{3}}{7 \alpha_{1}^{3}-15 \alpha_{1}^{2} \beta+10 \alpha_{1}^{2} \alpha_{2}-\alpha_{1} \beta^{2}-2 \alpha_{1} \alpha_{2} \beta+\beta^{3}}$, the two are affected in the same way. When $\frac{\alpha_{1}^{3}-7 \alpha_{1}^{2} \beta+6 \alpha_{1}^{2} \alpha_{2}+\alpha_{1} \beta^{2}-2 \alpha_{1} \alpha_{2} \beta+\beta^{3}}{7 \alpha_{1}^{3}-15 \alpha_{1}^{2} \beta+10 \alpha_{1}^{2} \alpha_{2}-\alpha_{1} \beta^{2}-2 \alpha_{1} \alpha_{2} \beta+\beta^{3}}<\rho<1$, the direct selling channel is more affected.

Thus, the larger the market share is, the worse of the stability when in disruption. 